\title{
Numerical and Experimental Analyses on Motion Responses on Heaving Point Absorbers Connected to Large Semi-Submersibles
}

\author{
Kyong-Hwan Kim ${ }^{1}\left(\mathbb{D}\right.$, Sewan Park ${ }^{1}$, Jeong-Rok Kim ${ }^{2}$, Il-Hyoung Cho ${ }^{2}\left(\mathbb{D}\right.$ and Keyyong Hong ${ }^{1, *}(\mathbb{1})$ \\ 1 Marine Renewable Energy Research Division, Korea Research Institute of Ships and Ocean Engineering, \\ Daejeon 34103, Korea; kkim@kriso.re.kr (K.-H.K.); sewanpark@kriso.re.kr (S.P.) \\ 2 Department of Ocean System Engineering, Jeju National University, Jeju 63243, Korea; \\ wodqks1005@jejunu.ac.kr (J.-R.K.); cho0904@jejunu.ac.kr (I.-H.C.) \\ * Correspondence: khong@kriso.re.kr
}

check for

updates

Citation: Kim, K.-H.; Park, S.; Kim, J.-R.; Cho, I.-H.; Hong, K. Numerical and Experimental Analyses on

Motion Responses on Heaving Point Absorbers Connected to Large Semi-Submersibles. Processes 2021, 9 , 1363. https://doi.org/10.3390/ pr9081363

Academic Editor: Krzysztof Rogowski

Received: 4 July 2021

Accepted: 2 August 2021

Published: 3 August 2021

Publisher's Note: MDPI stays neutral with regard to jurisdictional claims in published maps and institutional affiliations.

Copyright: (c) 2021 by the authors. Licensee MDPI, Basel, Switzerland. This article is an open access article distributed under the terms and conditions of the Creative Commons Attribution (CC BY) license (https:/ / creativecommons.org/licenses/by/ $4.0 /)$.

\begin{abstract}
This study considers the motion responses of heaving point absorbers (HPAs) connected to large semi-submersibles. To analyze the motion responses for HPAs, a motion response amplitude operator (RAO) of a single HPA connected to a fixed wall was obtained in a two-dimensional wave flume. A frequency-domain eigenvalue analysis is used to evaluate the motion RAO of a single HPA, and the experimental and numerical results of motion RAO were compared. A model test was conducted to analyze the motions of multiple HPAs connected to a large semi-submersible in a 3D ocean basin. The motion RAOs of the multiple HPAs connected to the large semi-submersible were compared with the motion RAO of the single HPA connected to the fixed wall.
\end{abstract}

Keywords: wave energy converter; heaving point absorber; semi-submersible; motion RAO

\section{Introduction}

With the increase in global warming, research on renewable energy sources is accelerating worldwide. Since the past 10 years, demand for renewable power supply has been increasing rapidly, especially wind and solar power supplies. In addition, research on marine energy is being actively conducted as a future energy resource. Marine energy has various forms, such as waves, wind, and tides. Various power-generation devices related to marine energy have been developed, and in recent years, efforts have been made to improve economic efficiency. The combination of wave power and offshore wind power can generate more energy in a confined space; this is called hybrid power generation. These systems have the advantage of combining multiwave energy converters (HPAs) with wind turbines (WTs), which can enhance the energy yield, share the common grid and substructure, obtain smooth power output, and share operation and maintenance. The merits of combining wave and offshore wind and recent research trends are summarized in [1].

A 10 MW class floating wave-offshore wind hybrid power generation system was developed in 2016, as shown in Figure 1, where multiple WTs and HPAs were placed in one large semi-submersible with a spread mooring system. However, WTs and HPAs are influenced by wind, wave, and tidal loads, while floating platforms and mooring systems are affected by wave and tidal loads. Each of these components is loaded with each other and forms a mechanically complex system. In this Korean research project, various studies have been performed, including CFD-based interaction analysis of multiple WTs, hydrodynamic analysis of a single HPA based on a potential flow analysis and model tests on a wave tank, time-domain fully coupled analysis of the entire system, and integrated model tests on 3D ocean basins [2-7]. To analyze the power generation performance of multiple WTs and HPAs, a coupled analysis is required that combines the dynamics of multiple WTs and HPAs, floating platforms, and mooring systems. 


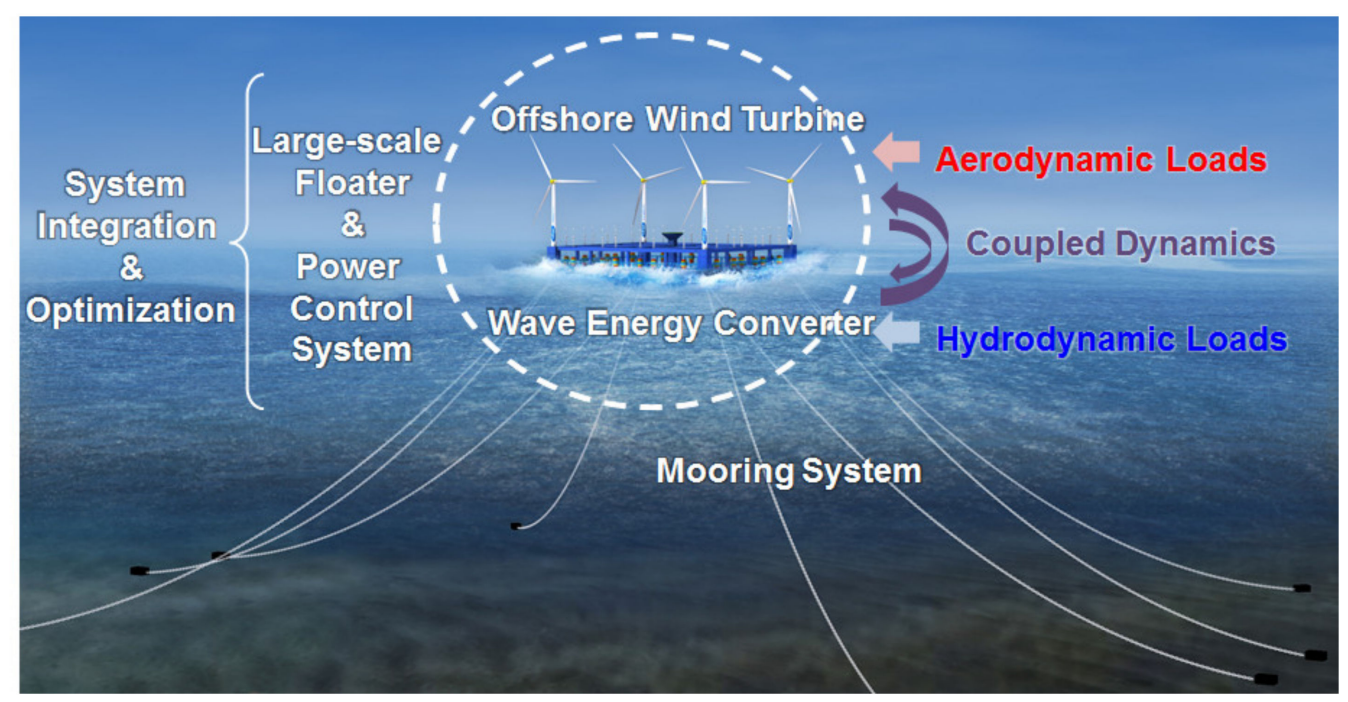

Figure 1. Concept of wave-offshore hybrid power-generation system [2].

This study focuses on the motion responses of the HPAs used in the project. Many previous studies have been conducted to analyze the motion response and the efficiency of single and multiple HPAs [8-18]. The HPA is composed of a buoy and linear generator in this study. The buoy only moves up and down owing to the incoming waves on the free surface between the deck and pontoon of the semi-submersible. The other motions, except the heave motion, are constrained. A potential flow-based eigenvalue analysis was applied to analyze the motion responses of a single HPA. Next, a model test was performed on the HPA in the wave tank, and the results were compared with those of the eigenvalue analysis to confirm the motion responses of the HPA. Model tests were performed in a three-dimensional (3D) ocean basin to analyze the motion responses of multiple HPAs mounted on large semi-submersibles. First, the motion RAO of the large semi-submersible platform was compared with the results of the 3D potential flow analysis and verified. Then, motion RAOs of multiple HPAs mounted on a large semi-submersible were evaluated and compared with the results of a single HPA. Accordingly, the motion characteristics of multiple HPAs attached to large semi-submersibles are discussed.

\section{Numerical Methods}

\subsection{Target Model}

The overall structure covered in this study is composed of the hull, HPA, WT, and mooring system. The floating structure is a semi-submersible comprising columns, pontoons, and braces. Twenty-four HPAs were placed along each side of the semi-submersible, each comprising a buoy, guide frame, and guide mounting. Four wind turbines are arranged at each corner of the semi-submersible, each comprising a tower, nacelle, and rotor. The semi-submersible is moored at four points using eight mooring lines. Figure 2 shows the shape of the large semi-submersible and HPA. The guide mounting is used to mount the buoy, and the guide frame, which is a vertical pillar, supports the guide mounting from the left and right. 


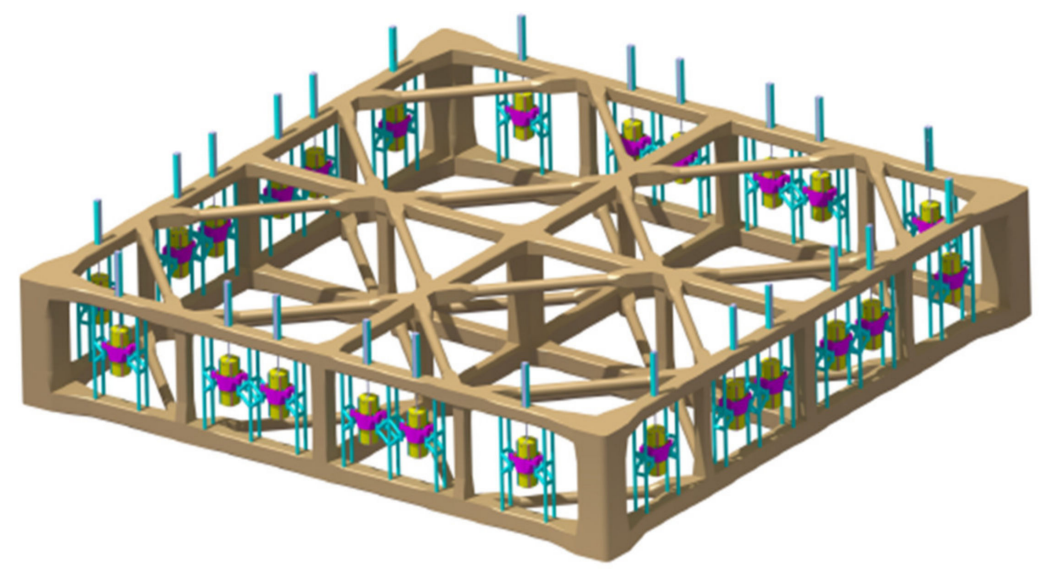

(a)

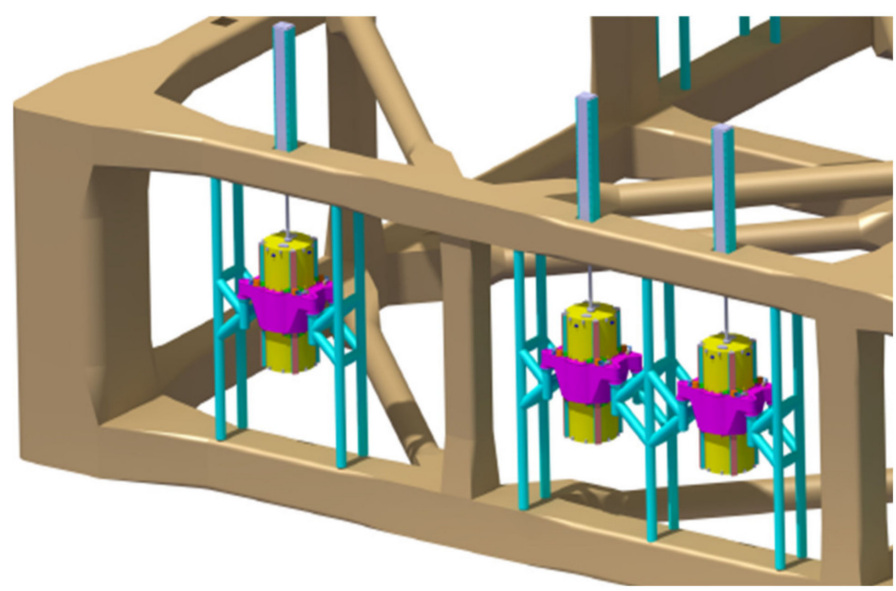

(b)

Figure 2. (a) Large semi-submersible; (b) Wave energy converter.

\subsection{Single HPA}

The motion response of the single HPA is analyzed by eigenvalue analysis presented in [7]. The diffraction and radiation of waves by a single HPA of cylindrical shape, with radius $a$ and draft $d$, floating in open water of uniform depth $h$, are considered. A cylindrical coordinate system was chosen for the analysis, with the origin at the center of the HPA on the free surface and the $z$-axis pointing vertically upward. Under the assumption of linear potential theory, fluid velocity can be described by the gradient of the velocity potential, $\Phi(\mathrm{r}, \theta, \mathrm{z}, \mathrm{t})$. Assuming harmonic motion with frequency $\omega$, the velocity potential can be written as $\Phi(r, \theta, z, t)=\operatorname{Re}\left[\phi(r, \theta, z) e^{-i \omega t}\right]$ The total velocity potential can be expressed as the sum of diffraction potential $\phi_{D}$ (incident wave + scattering wave potential) and radiation potential $\phi_{R}$.

$$
\begin{aligned}
\phi(r, \theta, z) & =-\frac{i g}{\omega} A\left[\phi_{I}(r, \theta, z)+\phi_{S}(r, \theta, z)\right]-i \omega \xi \phi_{R}(r, z), \\
& =-\frac{i g}{\omega} A \sum_{l=0}^{\infty}\left[\phi_{I}^{l}(r, z)+\phi_{S}^{l}(r, z)\right] \cos l \theta-i \omega \xi \phi_{R}(r, z)
\end{aligned}
$$

where $A$ is the incident wave amplitude, and $\xi$ is the complex heave amplitude of the HPA. In this study, only heave motion is considered, although the inclusion of other degrees of freedom is straightforward. As the body of HPA is axisymmetric, the heave mode is independent of the other modes. 
The fluid is divided into regions (I) and (II) to apply the matched eigenfunction expansion method (MEEM). Regions (I) and (II) are defined by $r>a,-h<z<0$ and $r<a,-h<z<-d$, respectively. The diffraction potential in region (I), satisfying the Laplace equation in fluid, linear free-surface condition, bottom condition, and radiation condition, can be expressed as

$$
\phi_{D}^{l(1)}=\beta_{l} J_{l}\left(k_{1} r\right) \frac{\cosh k_{1}(z+h)}{\cosh k_{1} h}+\sum_{n=0}^{\infty} B_{l n} \frac{K_{l}\left(k_{1 n} r\right)}{K_{l}\left(k_{1 n} a\right)} \psi_{1 n}(z)
$$

where $\beta_{l}$ is defined by $\beta_{l}=1$ if $l=0$ and $\beta_{l}=2(i)^{l}$ if $l \geq 0$. Here, $n=0$ denotes the propagating mode, while $n \geq 1$ represents evanescent modes. $J_{l}$ and $K_{l}$ are Bessel and modified Bessel functions, respectively.

The eigenvalues $\left(k_{10}=-i k_{1}, k_{1 n}, n=1,2, \ldots\right)$ in region (I) satisfy the dispersion relation, $k_{1 n} \operatorname{tank}_{1 n} h=-\omega^{2} / g$ and the normalized eigenfunctions can be written as

$$
\begin{aligned}
& \psi_{1 n}(z)=N_{1 n}^{-1} \cos k_{1 n}(z+h), \quad n=0,1,2, \ldots \\
& \left(N_{1 n}\right)^{2}=\frac{1}{2}\left(1+\frac{\sin 2 k_{1 n} h}{2 k_{1 n} h}\right) .
\end{aligned}
$$

Eigenfunctions $\Psi_{1 n}$ satisfy following orthogonal relation:

$$
\frac{1}{h} \int_{-h}^{0} \psi_{1 m}(z) \psi_{1 n}(z) d z=\delta_{m n}
$$

where $\delta_{m n}$ is the Kronecker delta function, defined by $\delta_{m n}=1$ if $m=n$ and $\delta_{m n}=0$ if $m \neq n$.

The velocity potential in region (II), satisfying the Laplace equation and the bottom condition, can be written as

$$
\phi_{D}^{l(2)}=A_{l 0}\left(\frac{r}{a}\right)^{l}+2 \sum_{n=1}^{\infty} A_{l n} \frac{I_{l}\left(\lambda_{n} r\right)}{I_{l}\left(\lambda_{n} a\right)} \cos \lambda_{n}(z+h)
$$

where $\lambda_{n}=\frac{n \pi}{h-d},(n=0,1,2, \ldots)$.

The velocity potential in each region should satisfy the boundary matching condition, that is, $\phi$ and $\partial \phi / \partial r$ are continuous across $r=a$. If the matching equation for $\phi$ is multiplied by a set of eigenfunctions $\left\{\cos \lambda_{m}(z+h), m=0,1,2, \ldots\right\}$ and integrated over $(-h,-d)$, the matching equation for $\partial \phi / \partial r$ is multiplied $\left\{\Psi_{1 m}(z), m=0,1,2, \ldots\right\}$ and integrated over $(-h, 0)$, and $A_{l m}$ is eliminated from the resulting equations, to obtain the following equations:

$$
B_{l m}-\frac{2}{q_{l m}} \sum_{n=0}^{N}\left(\sum_{k=0}^{N} p_{l k} G_{k n} G_{k m}\right) B_{l n}=\frac{1}{q_{l m}}\left(-\frac{\beta_{l} k_{1} h J_{l}^{\prime}\left(k_{1} a\right) N_{10}}{\cosh k_{1} h} \delta_{m 0}-2 \sum_{k=0}^{\infty} p_{l k} q_{l k} G_{k m}\right), \quad m=0,1,2, \ldots, N
$$

where

$$
\begin{gathered}
G_{m n}=\frac{1}{(h-d)} \int_{-h}^{-d} \cos \lambda_{m}(z+h) \psi_{1 n}(z) d z \\
p_{l n}= \begin{cases}\frac{(h-d) l}{2 a}, & n=0 \\
\frac{\lambda_{n}(h-d) I_{l}^{\prime}\left(\lambda_{n} a\right)}{I_{l}\left(\lambda_{n} a\right)}, & n \geq 1\end{cases} \\
q_{l n}=\frac{k_{1 n} h K_{l}^{\prime}\left(k_{1 n} a\right)}{K_{l}\left(k_{1 n} a\right)}, \quad n \geq 0 .
\end{gathered}
$$


These matrix equations can be solved by truncating $m$ and $n$ to $N$ for a given integer, $l=0,1,2, \ldots, M$. The unknown coefficient, $A_{l m}$, can be obtained from the following equation:

$$
A_{l m}=\sum_{n=0}^{N} B_{l n} G_{m n}+\frac{\beta_{l} J_{l}\left(k_{1} a\right) N_{10}}{\cosh k_{1} h} G_{m 0}, m=0,1, \ldots, N .
$$

Based on the solutions of the velocity potential, the vertical wave exciting forces on the HPA can be determined by integrating the pressure over its bottom surface.

$$
F_{D}=\operatorname{Re}\left\{A X e^{-i \omega t}\right\}, \text { with } X=2 \pi \rho a \int_{0}^{a} r \phi_{D}^{0(2)}(r,-d) d r .
$$

The radiation problem caused by the vertical oscillation of the HPA can be solved similarly to the diffraction problem. The velocity potentials in regions (I) and (II) can be expressed as

$$
\begin{aligned}
& \phi_{R}^{(1)}=\sum_{n=0}^{\infty} B_{n}^{*} \frac{K_{0}\left(k_{1 n} r\right)}{K_{0}\left(k_{1 n} a\right)} \psi_{1 n}(z), \\
& \phi_{R}^{(2)}=\phi_{P}^{(2)}+\sum_{n=0}^{\infty} \varepsilon_{n} A_{n}^{*} \frac{I_{0}\left(\lambda_{n} r\right)}{I_{0}\left(\lambda_{n} a\right)} \cos \lambda_{n}(z+h),
\end{aligned}
$$

where $\varepsilon_{n}=1$ if $n=0$, and $\varepsilon_{n}=2$ if $n \geq 1$. The particular solution in region (II) satisfying the inhomogeneous body-boundary condition $\left(\partial \phi_{P}^{(2)} / \partial z=1\right.$ at $\left.z=-d\right)$ is given by

$$
\phi_{P}^{(2)}=\frac{1}{2(h-d)}\left((z+h)^{2}-\frac{r^{2}}{2}\right) .
$$

From the boundary matching condition, we obtain the following algebraic equations:

$$
B_{m}^{*}-\frac{2}{q_{0 m}} \sum_{n=0}^{N}\left(\sum_{k=0}^{N} p_{0 k} G_{k n} G_{k m}\right) B_{n}^{*}=\frac{1}{q_{0 m}}\left(-\frac{a}{2} G_{0 m}-2 \sum_{k=0}^{\infty} p_{0 k} q_{0 k} G_{k m}\right), \quad m=0,1,2, \ldots, N
$$

The remaining unknown coefficients, $A_{m}^{*}$, in region (II) can then be determined as

$$
A_{m}^{*}=\sum_{k=0}^{N} B_{k}^{*} G_{m k}-\frac{1}{(h-d)} \int_{-h}^{-d} \phi_{P}^{(2)}(a, z) \cos \lambda_{m}(z+h) d z
$$

The hydrodynamic forces caused by the heave oscillation of the HPA are determined by integrating pressure over the bottom surface of the cylinder.

$$
\begin{aligned}
F_{R} & =\operatorname{Re}\left\{f_{R} e^{-i \omega t}\right\}, \text { with } f_{R}=2 \pi \rho \omega^{2} \xi \int_{0}^{a} r \phi_{R}^{(2)}(r,-d) d r \\
& =\left(\omega^{2} \mu+i \omega v\right) \xi,
\end{aligned}
$$

where $\mu$ and $v$ are the coefficients of the added mass and radiation damping, respectively.

The HPA is subjected to wave-exciting force $F_{D}(t)$, hydrostatic force $F_{S}(t)(=-\rho g S z)$, radiation force $F_{R}(t)$, and several damping forces (viscous damping $F_{v}(t)$ and power takeoff (PTO) damping $F_{\text {PTO }}(t)$ ). The equation of the heave motion for the HPA system can be described by Newton's second law:

$$
m \ddot{z}=F_{D}(t)+F_{S}(t)+F_{R}(t)+F_{v}(t)+F_{m}(t)+F_{P T O}(t)
$$

where the upper dot denotes time derivatives, $m(=\rho S d)$ is the mass of the buoy along with the attached equipment, and $S\left(=\pi a^{2}\right)$ is the water plane area.

The viscous damping force can be linearly described as

$$
F_{v}(t)=-b_{v} \dot{z}
$$

where viscous damping coefficient $b_{v}$ is calculated from $b_{v}=2 \kappa \rho g S / \omega_{N}$, and $\kappa$ is the dimensionless damping factor, which can be obtained from the free-decay test [9]. Further, 
$\omega_{N}\left(=\sqrt{\frac{\rho g S}{m+\mu\left(\omega_{N}\right)}}\right.$ is the undamped heave natural frequency, where $\mu\left(\omega_{N}\right)$ is the added mass at the heave natural frequency. In this study, the linear viscous model expressed by Equation (15) was used with the viscous damping coefficient obtained from the free-decay test. The mechanical damping can be assumed to be proportional to the heave velocity $F_{m}(t)=-b_{m} \dot{z}$.

$F_{P T O}(t)$ is the PTO damping force, modeled as an equivalent linear damping force, given by

$$
F_{P T O}(t)=-b_{P T O} \dot{z}
$$

where $b_{P T O}$ is the linear external damping coefficient of the PTO, enabling power extraction, and it depends on the winding geometry, the configuration of the stator rotor, and driving frequency. The (dry) bench test is the most reliable method for evaluating these coefficients, even though electromagnetic computations using finite element methods are possible.

The following heave RAO of the HPA is obtained by assuming harmonic motion, $z(t)=\operatorname{Re}\left\{\xi e^{-i \omega t}\right\}$ :

$$
\left|\frac{\xi}{A}\right|^{2}=\frac{|X|^{2}}{\left[\rho g S-\omega^{2}(m+\mu)\right]^{2}+\left[\omega b_{\text {PTO }}(1+f)\right]^{2}}
$$

where $b_{T}=b_{v}+b_{m}+v, f=b_{P T O} / b_{T}$.

The time-mean mechanical power, $\bar{P}$, being input to the linear electric generator (LEG) is given by

$$
\frac{\bar{P}}{A^{2}}=\frac{1}{2} b_{\text {PTO }} \omega^{2}\left|\frac{\xi}{A}\right|^{2}
$$

$\bar{P}$ is maximized if the dynamic resonance condition $\left(\omega=\omega_{N}\right)$ is satisfied, and PTO damping $\left(b_{P T O}\right)$ is equal to the total damping $\left(b_{T}\right)$, resulting in

$$
\frac{\bar{P}_{\max }}{A^{2}}=\frac{1}{8} \frac{|X|^{2}}{b_{T}}
$$

For irregular waves, the heave-motion and square-root-power spectra are respectively computed as

$$
\begin{aligned}
& S_{z}(\omega)=\left|\frac{\xi}{A}\right|^{2} \cdot S_{I}(\omega), \\
& S_{\sqrt{P}}(\omega)=\frac{\bar{P}(\omega)}{A^{2}} \cdot S_{I}(\omega) .
\end{aligned}
$$

The JONSWAP spectrum is used as the incident wave spectrum, $S_{I}(\omega)$, denoted as

$$
\begin{aligned}
& S_{I}(\omega)=\beta \frac{H_{1 / 3}^{2} \omega_{P}^{4}}{\omega^{5}} \exp \left[-1.25\left(\frac{\omega}{\omega_{P}}\right)^{-4}\right] \gamma^{\exp \left[-\frac{\left(\omega-\omega_{P}\right)^{2}}{2 \sigma^{2} \omega_{P}^{2}}\right]}, \\
& \text { with } \beta=\frac{0.0624}{0.23+0.0336 \gamma-0.185(1.9+\gamma)^{-1}}(1.094-0.01915 \ln \gamma),
\end{aligned}
$$

where $H_{1 / 3}$ is the significant wave height, and $\omega_{P}\left(=\frac{2 \pi}{T_{P}}\right)$ is the peak frequency. $\gamma=3.3$ and $\sigma=0.07$ for $\omega<\omega_{P}$, and $\sigma=0.09$ for $\omega \geq \omega_{P}$.

The significant heave-motion amplitude and significant amplitude of the square root power in irregular waves can be obtained as

$$
\begin{aligned}
& \xi_{1 / 3}=2 \sqrt{\int_{0}^{\infty} S_{z}(\omega) d \omega}, \\
& \sqrt{P}_{1 / 3}=2 \sqrt{\int_{0}^{\infty} S_{\sqrt{P}}(\omega) d \omega} .
\end{aligned}
$$

Figure 3 shows the time-mean mechanical power according to the PTO damping coefficient. The extracted power shows a peak value at a specific PTO damping coefficient 
$(38 \mathrm{~kg} / \mathrm{s})$, and this value is used in the initial design stage of the LEG. Figure 4 shows the heave RAO of the HPA with the optimal PTO damping coefficient. The peak value of the heave RAO curve is approximately 1.5 , and it occurs at the heave motion resonant frequency $\left(\omega_{N}=3.8 \mathrm{rad} / \mathrm{s}\right)$ of the HPA.

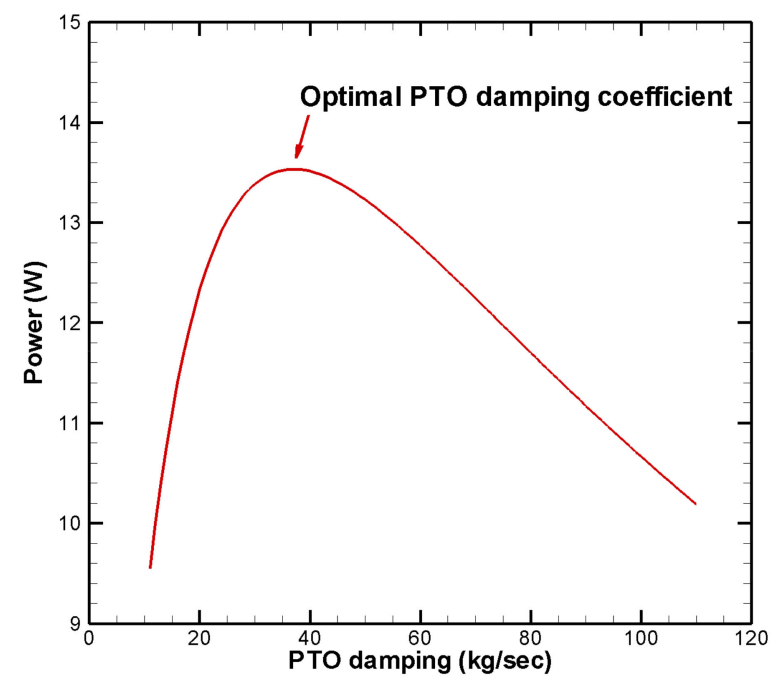

Figure 3. Time-mean extracted power according to the PTO damping coefficient.

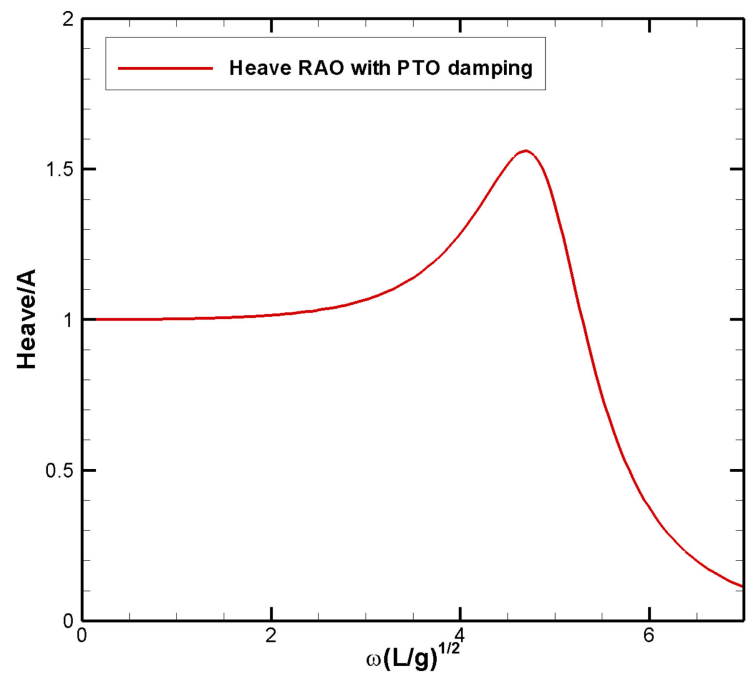

Figure 4. Heave RAO of the HPA applied with the optimal PTO damping coefficient.

\subsection{Large Semi-Submersible}

The motion response of a large semi-submersible can be analyzed using potential flow analysis. In this study, the hydrodynamic coefficient of the large semi-submersible structure was evaluated using the WADAM of DNV-GL, a Green function-based potential flow analysis program. Figure 5 shows the panel model of the large semi-submersible for the potential flow analysis. ORCAFLEX, a time-domain analysis program, was used for the coupled analysis of the mooring system and large semi-submersible. In the analysis, a quadratic transfer function was applied based on Newman's approximation. Tidal currents and wind loads were derived using WINDOS (a program that provides a cost-effective way to assess the wind loads on offshore constructions developed by MARIN). 


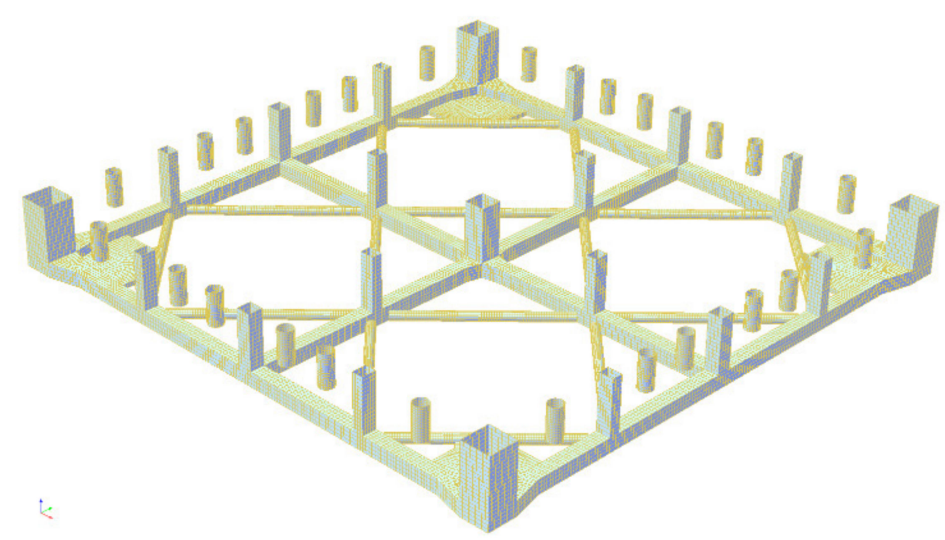

Figure 5. Panel model of the large semi-submersible structure.

\section{Experimental Setup}

\subsection{Single HPA}

To evaluate the performance of the HPA, a model test for a single HPA was performed using a 1/10 scale model. Table 1 lists the main particulars of a single HPA. The model test was conducted in a wave tank at Seoul National University, and the length, breadth, and depth of the tank were 110,8 , and $3.5 \mathrm{~m}$, respectively.

Table 1. Main particulars of the HPA (scale 1:10).

\begin{tabular}{cccc}
\hline Item & Unit & Real & Model \\
\hline Weight & $\mathrm{kg}$ & 64,400 & 62.8 \\
Diameter & $\mathrm{M}$ & 4 & 0.4 \\
Draft & $\mathrm{M}$ & 5 & 0.5 \\
Heave natural period & $\mathrm{rad} / \mathrm{sec}$ & 1.26 & 3.8 \\
\hline
\end{tabular}

Figure 6 shows the HPA and PTO systems installed in the wave tank. The buoy is made of acrylic, and only vertical movement is allowed by the guide mounting. A roller is applied to minimize the mechanical friction between the buoy and guide mounting, and a ball joint is applied to the shaft and connection.
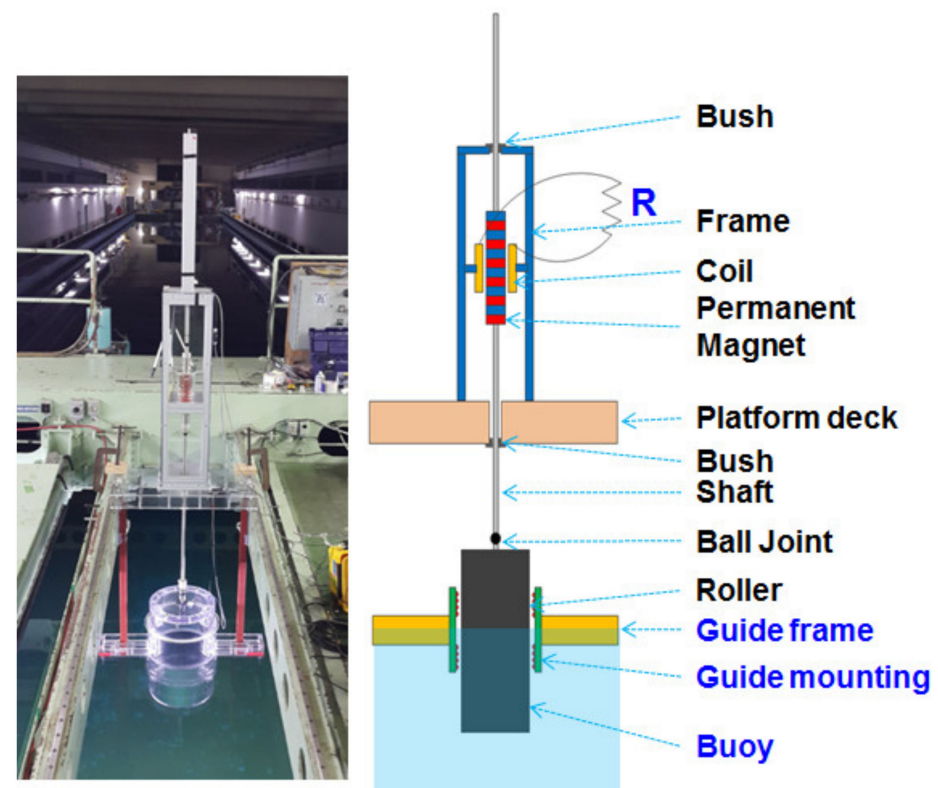

Figure 6. Photograph of a 1/10 scale model and experimental setup. 
As a PTO system, an LEG composed of permanent magnets and coils was manufactured and applied to generate electrical power. The permanent magnets were placed on the shaft above the platform deck. Load resistance was applied by passing a current through the coil, and the movement of the buoy was measured using an accelerometer (AS-1GB).

Table 2 shows the results of the free decay test according to PTO damping. In the free decay test, only the vertical motion was allowed by the guide mounting. M00 implies no resistor, and M15 and M06 represent the cases where 15- and 6- $\Omega$ resistors of the LEG are connected. The overall damping of HPA can be derived from the free decay test which includes PTO damping, radiation damping, mechanical frictional damping, and viscous damping. When the time-series decay tests were conducted using the model in still water, as shown in Figure 7, the damping ratio $(\kappa)$ was easily determined by the ratio between any pair of successive amplitudes, $z_{a i},(i=1,2, \ldots)$ as follows:

$$
\kappa=\frac{1}{2 \pi} \ln \left\{\frac{z_{a 1}-z_{a 2}}{z_{a 3}-z_{a 4}}\right\} .
$$

Table 2. Free decay test of single HPA with PTO damping.

\begin{tabular}{ccccc}
\hline Case & $\begin{array}{c}\text { Resistance } \\
(\boldsymbol{\Omega})\end{array}$ & $\begin{array}{c}\text { PTO Damping } \\
\text { Coefficient }(\mathbf{k g} / \mathbf{s})\end{array}$ & $\begin{array}{c}\text { Total Damping } \\
\text { Coefficient }(\mathbf{k g} / \mathbf{s})\end{array}$ & Damping Ratio $(\kappa)$ \\
\hline M00 & 0 & 0 & 60.15 & 9.6 \\
M15 & 15 & 17.17 & 77.32 & 12.4 \\
M06 & 6 & 40.73 & 100.88 & 16.1 \\
\hline
\end{tabular}

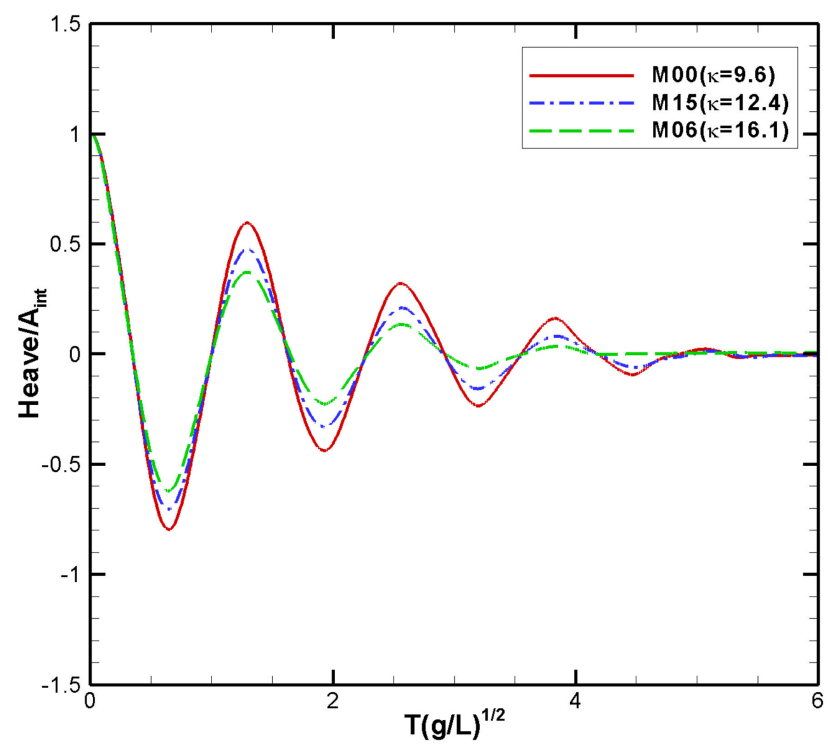

Figure 7. Free decay test of single HPA with different PTO damping coefficients.

Even in the absence of a resistor, a damping ratio $(\kappa)$ of 9.6 occurs in M00, which can be regarded as radiation, mechanical, and viscous damping. The damping coefficient can be obtained using $b=2 \kappa \rho g S / \omega_{N}$. The PTO damping coefficients, $b_{P T O}$, for M15 and M06 were calculated by subtracting the M00 results from M15 and M06. The PTO damping coefficients for M15 and M06 were found to be 17.17 and $40.73 \mathrm{~kg} / \mathrm{s}$, respectively. Notably, when the load resistance is connected to $6 \Omega$, the PTO damping coefficient is very close to the theoretically calculated optimal PTO damping coefficient $(38 \mathrm{~kg} / \mathrm{s})$.

During normal operation of the HPA, the PTO damping force $\left(F_{\text {PTO }}=B \cdot i \cdot L\right)$ is derived from the LEG using the Lorentz force equation, where $B$ is the magnitude of the magnetic flux density, $i(=V(t) / R)$ is the induced current, and $L$ is the total length of the coil. The PTO damping force decreases the heave motion. The magnetic flux density and coil length are fixed variables determined by the LEG configuration. To generate current using the 
LEG, resistance $R$ was connected to the coil. Then, voltage $(V)$ originating from the heave motion of the HPA was measured. Consequently, the time-mean electrical power, $\bar{P}_{\text {elec }}$, was calculated from the induced current and resistance $R$ :

$$
\bar{P}_{\text {elec }}=\frac{1}{T} \int_{t}^{t+T} i^{2}(t) R d t
$$

The efficiency of the LEG is defined as $\eta_{\text {elec }}=\bar{P}_{\text {elec }} / \bar{P}$ to quantify the electricity conversion process within a linear generator with mechanical power input.

\subsection{Multiple HPAs Connected to a Large Semi-Submersible}

A model test was performed on multiple HPAs to evaluate their performance on the $1 / 50$ scale when connected to a large semi-submersible structure. Table 3 shows the specifications of the HPAs and large semi-submersible. The model test was conducted in the ocean basin of KRISO.

Table 3. Specifications of multiple HPAs and large semi-submersible (scale 1:50).

\begin{tabular}{ccccc}
\hline Part & Item & Unit & Prototype & Model \\
\hline \multirow{6}{*}{ Platform } & ton & 27,266 & 0.218128 \\
& Displacement & $\mathrm{m}$ & 15 & 0.3 \\
& Draft (Design) & $\mathrm{m}$ & 150 & 3 \\
& Column Span (center to center) & $\mathrm{m}$ & 12 & 0.24 \\
& Column freeboard & $\mathrm{m}$ & 15.34 & 0.3068 \\
& Center of Gravity (CoG) above Keel & $\mathrm{m}$ & 62.24 & 1.2448 \\
& Roll Radius Gyration: Rxx & $\mathrm{m}$ & 62.3 & 1.246 \\
& Pitch Radius Gyration: Ryy & $\mathrm{m}$ & 84 & 1.68 \\
& Yaw Radius Gyration: Rzz & $\mathrm{m}$ & 104.35 & 2.087 \\
& GM (F.S Correction) & $\mathrm{m}$ & 20.27 & 2.8661 \\
& Heave Natural Period & $\mathrm{s}$ & 152.13 & 21.5149 \\
& Surge/Sway Natural Period & $\mathrm{s}$ & 20.33 & 2.8756 \\
& Roll/Pitch Natural Period & $\mathrm{s}$ & 88,000 & 0.704 \\
HPA & Buoy Weight & $\mathrm{kg}$ & 4 & 0.08 \\
& Buoy Diameter & $\mathrm{m}$ & 5 & 0.1 \\
\hline
\end{tabular}

Figure 8 shows the HPA model connected to a large semi-submersible structure. The radius of gyration was calculated through CAD modeling as the structure was too large for a swing test. The weights of all the parts, sensors, cables, and the DAQ device were considered in advance, and the center of gravity and inertia were matched to the target. The inertia radius was evaluated as a natural period through a free damping test, as shown in Table 4.

Table 4. Natural period of semi-submersible (real scale).

\begin{tabular}{ccccccc}
\hline Mode & Surge (sec) & Sway (sec) & Heave (sec) & Roll (sec) & Pitch (sec) & Yaw (sec) \\
\hline Exp. & 153.05 & 148.63 & 19.54 & 19.70 & 20.13 & 166.29 \\
Num. & 152.13 & 152.13 & 20.27 & 20.33 & 20.33 & 162.93 \\
Error & $0.6 \%$ & $-2.3 \%$ & $-3.7 \%$ & $-3.2 \%$ & $-1.0 \%$ & $2.0 \%$ \\
\hline
\end{tabular}




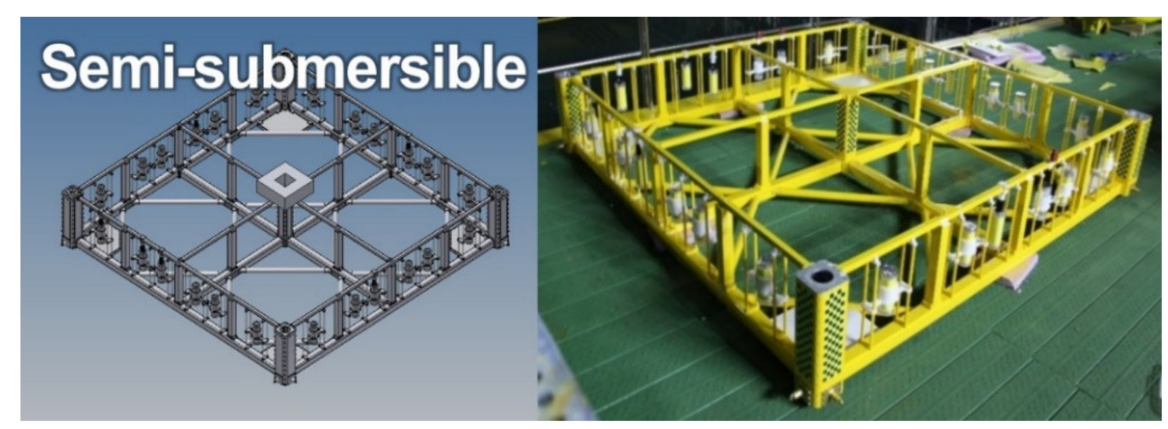

(a)

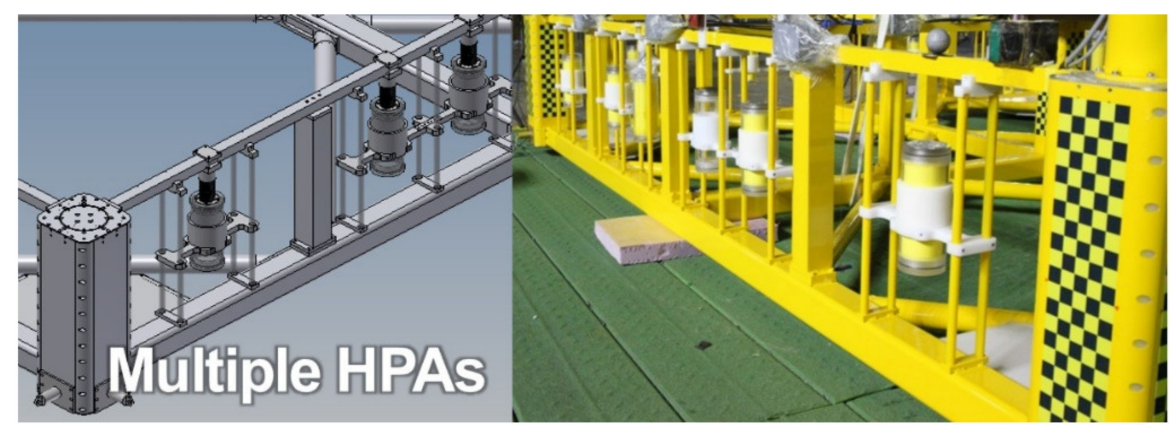

(b)

Figure 8. Test model (multiple HPAs and large semi-submersible); (a) Large semi-submersible; (b) Multiple HPAs.

The 6-DOF motion of the large semi-submersible structure was measured using an optical sensor (RODYM-6D), and the vertical motion of the buoy was measured using a laser sensor, as shown in Figure 9.

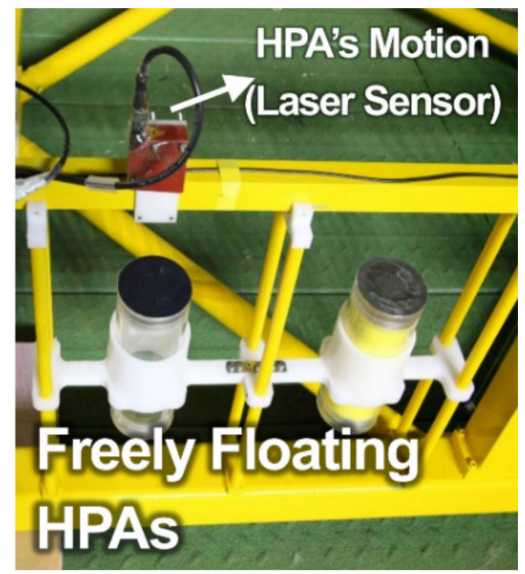

Figure 9. Measurement of HPA's motion.

It is important to apply a damping effect similar to that of a single HPA to the multiple HPAs connected to the semi-submersible. The effects of fluid viscosity and mechanical friction on multiple HPAs were different than those of a single HPA. The multiple HPAs connected to the large semi-submersible had little friction between the buoy and guide mount because no roller was attached to the mount. To match the effect of damping, a slipping tape was attached to the surface of the HPAs. Free decay tests on the buoy were performed while varying the area of the attached tape, and the area of the tape was set similar to the damping ratio in the no-resistor case in the single HPA experiment. Figure 10 shows the slipping tape attached to the buoy as well as the free decay signal measured at a 
damping ratio $(\kappa)$ of 9.0. Owing to the scale of this experiment, the embedding of the PTO damping system was not as easy as in the single HPA experiment.
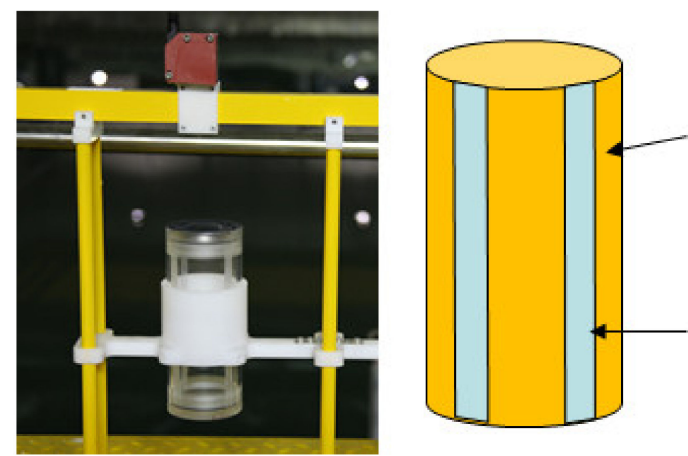

\section{Buoy}

\section{Slipping tape}

(a)

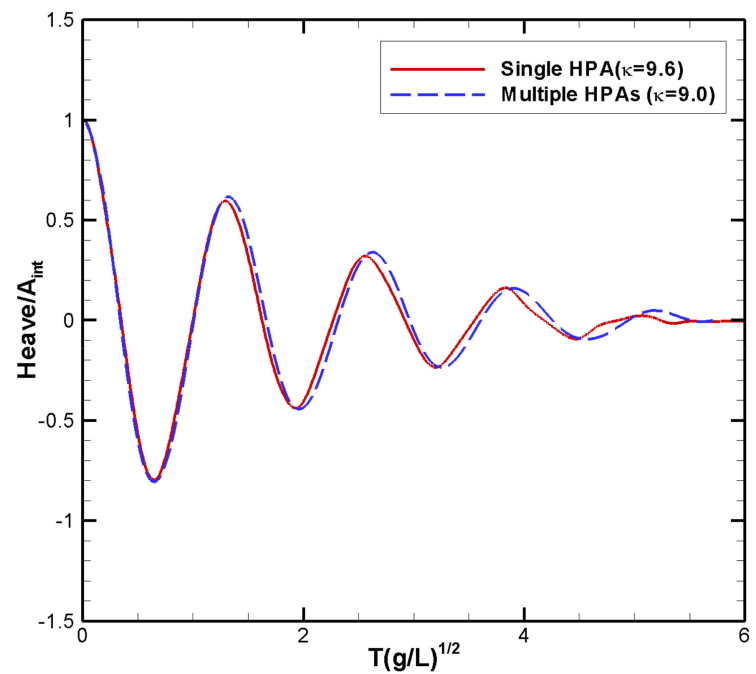

(b)

Figure 10. Free decay of HPA; (a) matching of HPA damping; (b) free decay of HPA connected to large semi-submersible.

Of the 24 HPAs, the motions of 3 were measured, the positions of which are shown in Figure 11. Two HPAs were placed on the weather side, while the third was placed on the lee side.

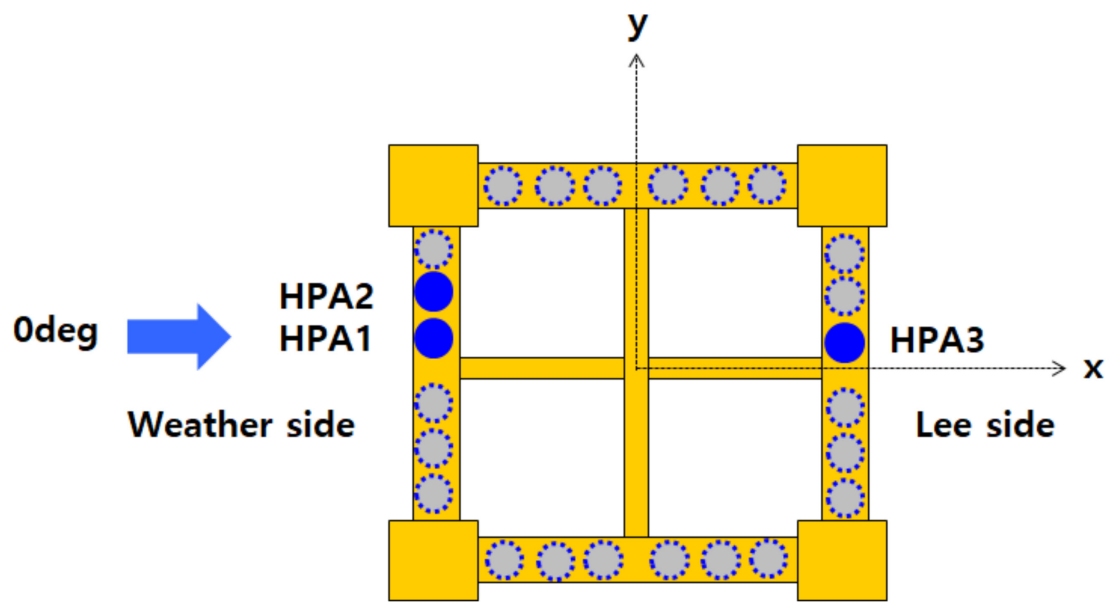

Figure 11. Location of HPAs for measurement of displacement. 
Each column of the semi-submersible is moored to a steel catenary by a 4-point, 8-wire mooring line, as shown in Figure 12. Table 5 lists the mooring specifications.

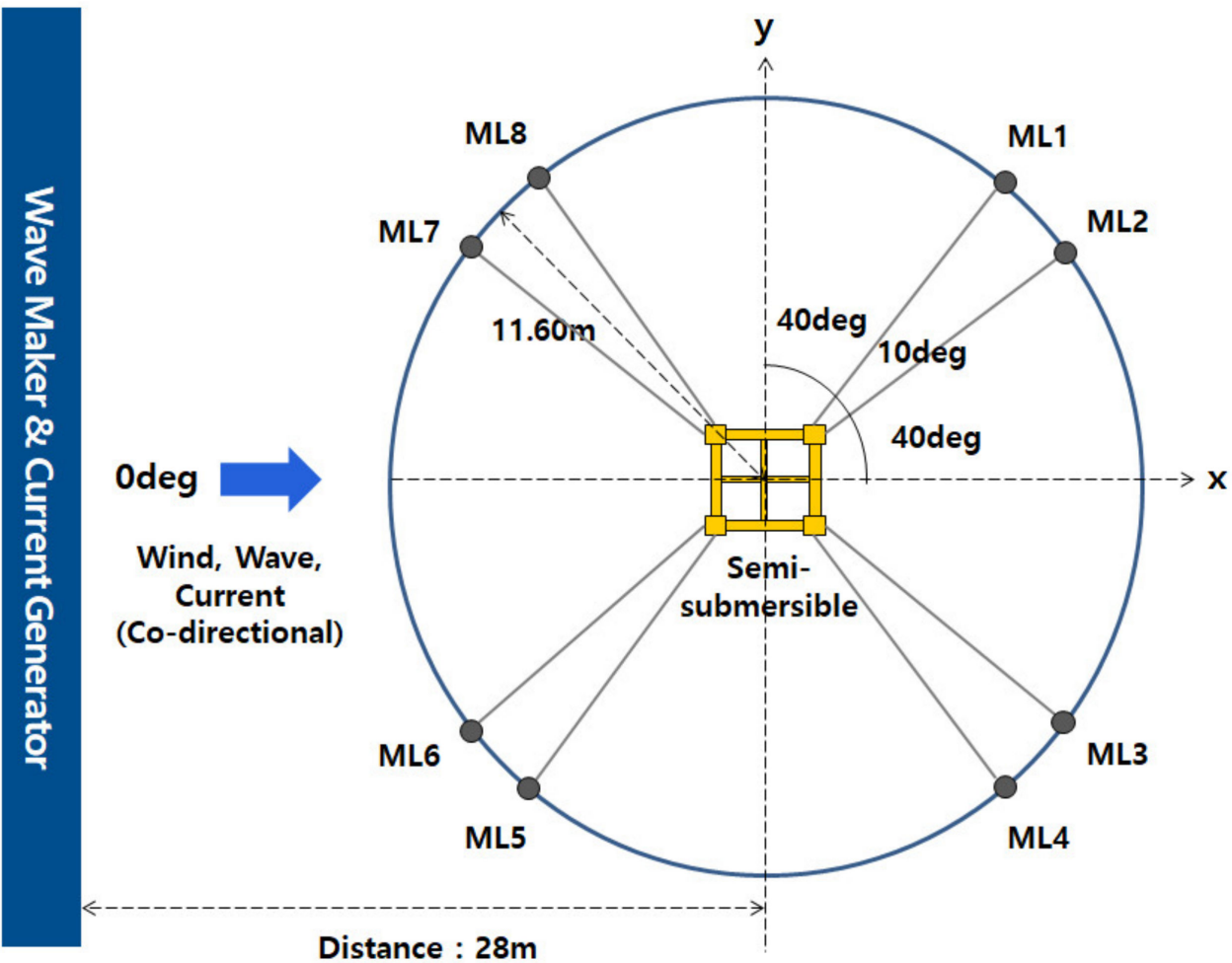

Figure 12. Configuration of semi-submersible and mooring line.

Table 5. Specifications of mooring lines (scale 1:50).

\begin{tabular}{cccc}
\hline Mooring Line Properties & Unit & Prototype & Model \\
\hline One-line Wet Weight & $\mathrm{kg}$ & 213,000 & 1.704 \\
Line Length & $\mathrm{m}$ & 500 & 10 \\
Clump Wet Weight & $\mathrm{kg}$ & 11,000 & 0.088 \\
Total Number of Clumps & $\mathrm{EA}$ & 6 & 6 \\
\hline
\end{tabular}

After the semi-submersible and mooring system were installed in the ocean basin, a free decay test was performed to verify the natural period of the model. Table 4 shows the natural period of the 6-DOF obtained through experimental evaluation and numerical analysis. All modes show an error of less than 5\%.

In the model test, where the semi-submersible and HPAs are connected, the motion RAO of the semi-submersible structure and HPAs is derived from regular waves. In addition, as shown in Table 6, irregular wave tests were performed under operational conditions and 1- and 10-year return period conditions. In the irregular wave conditions, the heading angles of wind, wave, and current are all applied at $0 \mathrm{deg}$.

Table 6. Test cases for irregular waves.

\begin{tabular}{ccccc}
\hline Condition & Hs $\mathbf{( m )}$ & $\mathbf{T p}(\mathbf{s})$ & $\mathbf{V c}(\mathbf{m} / \mathbf{s})$ & Wave Spectrum \\
\hline Operational condition & 3.00 & 6.67 & 0.14 & $\operatorname{JONSWAP}(\gamma=2.2)$ \\
1-y return period & 5.74 & 10.81 & 0.14 & $\operatorname{JONSWAP}(\gamma=2.2)$ \\
10-y return period & 7.67 & 12.40 & 0.14 & $\operatorname{JONSWAP}(\gamma=2.2)$ \\
\hline
\end{tabular}




\section{Results \& Discussion}

\subsection{Motion Responses of Single Heaving Point Absorber}

Regular wave tests were performed on the HPA models with a PTO system resistor of 15 and $0 \Omega$. The MEEM with the corresponding PTO damping coefficient, obtained from the free decay test, was applied to compare the experimental results with the analytical solutions.

In regular wave tests, the frequency range was selected as, $3.0 \mathrm{rad} / \mathrm{s} \leq \omega \leq 5.0 \mathrm{rad} / \mathrm{s}$ which includes the heave natural frequency $\left(\omega_{N}=3.8 \mathrm{rad} / \mathrm{s}\right)$ of the HPA, and a total of 10 wave frequencies were selected for the regular wave test. The wave steepness was fixed at 0.0144 . The experimental results were expressed as the heave RAO defined in Equation (17). Figure 13 shows the heave RAO of the HPAs with (M15, $\kappa=12.4$ denoted in Table 2) and without (M00, $\kappa=9.6)$ the PTO damping system. The heave RAO curve without the PTO system appears to be larger than the one with it in the entire frequency region. This is because the PTO system induces an additional PTO damping force, which can be observed from the free decay test. Both models show a peak value near the heave resonant frequency, where the peak value of M00 is approximately 2.0, which is larger than that of M15. The prediction tool developed in Section 3.1 accurately follows the trend of the experimental data. Although the prediction tool is based on the linear potential theory, it can be further improved by adding appropriate damping coefficients from the free-decay test. Model M15 produces electrical power when the vertical movement of the HPA generates current owing to the connected resistor.

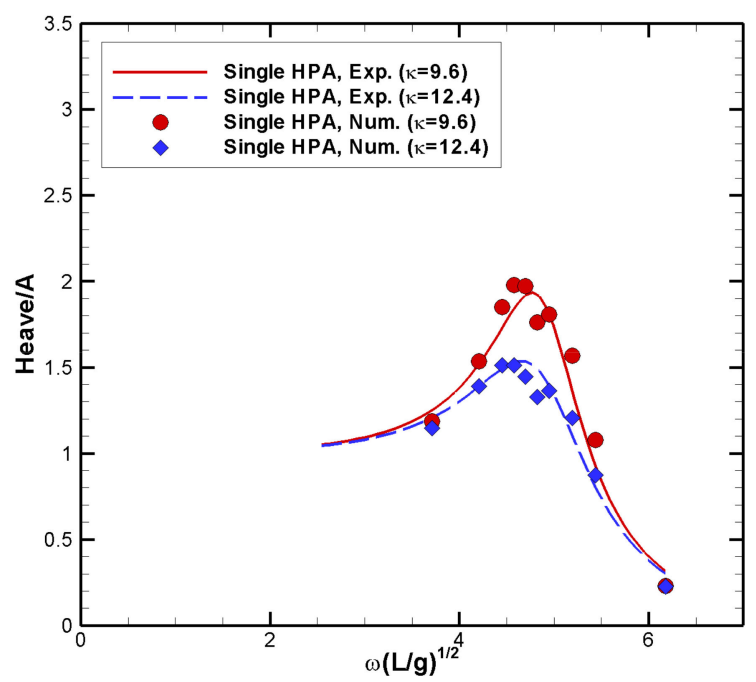

Figure 13. Heave RAO of single HPA with different PTO damping coefficients.

Table 7 shows the time-mean mechanical power obtained from the analytical solution and the electrical power obtained through experiments. The difference between them is due to the loss generated during the electricity conversion process within the linear generator. The extracted power is maximum at $\omega_{N}=3.6 \mathrm{rad} / \mathrm{s}$, slightly lower than the resonant frequency. It is also seen that the measured electrical power rapidly decreases in the highfrequency region past the resonant frequency. This is explained by the characteristics of the LEG system, which can generate power only when the heave motion displacement is greater than a certain value. The maximum value of the electrical power in the $1 / 10$ model test was approximately $0.5 \mathrm{~W}$. When scaling up to the full-sized prototype, an electrical power of $1.58 \mathrm{~kW}$ is extracted in the wave height $(H)$ and period $(T)$ of $H=0.6 \mathrm{~m}$ and $T=5.5 \mathrm{~s}$. Figure 14 shows the time series of the measured heave motion response and extracted power at the resonant frequency $\left(\omega_{N}=3.8 \mathrm{rad} / \mathrm{s}\right)$ for the M15 model. 
Table 7. Comparison of the time-mean extracted power between the analytical solutions and experimental results.

\begin{tabular}{ccccccccccc}
\hline Case & $\mathbf{1}$ & $\mathbf{2}$ & $\mathbf{3}$ & $\mathbf{4}$ & $\mathbf{5}$ & $\mathbf{6}$ & $\mathbf{7}$ & $\mathbf{8}$ & $\mathbf{9}$ & $\mathbf{1 0}$ \\
\hline $\begin{array}{c}\text { Frequency } \\
(\text { rad } / \mathrm{s})\end{array}$ & 3.0 & 3.4 & 3.6 & 3.7 & 3.8 & 3.9 & 4.0 & 4.2 & 4.4 & 5.0 \\
$\begin{array}{c}\text { Mechanical Power } \\
(\text { Cal.) }(\mathrm{W})\end{array}$ & 0.51 & 0.52 & 0.52 & 0.52 & 0.49 & 0.45 & 0.38 & 0.23 & 0.11 & 0.01 \\
$\begin{array}{c}\text { Electrical Power } \\
(\text { Exp.) }(\mathrm{W})\end{array}$ & 0.36 & 0.45 & 0.50 & 0.41 & 0.38 & 0.24 & 0.22 & 0.09 & 0.03 & 0.00 \\
$\quad \begin{array}{c}\text { Efficiency } \\
\eta_{\text {elec }}=\bar{P}_{\text {elec }} / \bar{P}\end{array}$ & 0.70 & 0.87 & 0.96 & 0.79 & 0.78 & 0.53 & 0.58 & 0.39 & 0.27 & 0.00 \\
\hline
\end{tabular}

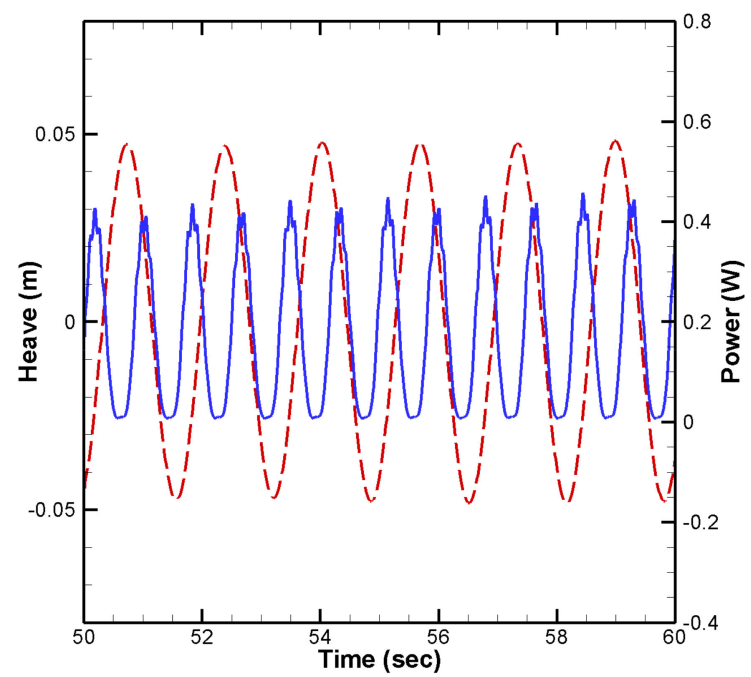

Figure 14. Time series of measured heave motion response and extracted power for M15 model at $\omega_{N}=3.8 \mathrm{rad} / \mathrm{s}$ (blue solid line = power, red dotted line $=$ heave).

Next, a model test in irregular waves was conducted for six different wave conditions (Table 8). The irregular wave test was performed in the same way as the regular wave, and model M06 was added to see the higher damping case, along with models M00 and M15. Representative statistical values were calculated from the time-series data over $600 \mathrm{~s}$. Figure 15 shows the analytical and experimental results for the heave RAO in the irregular wave tests which is defined by $2 \xi_{1 / 3} / H_{1 / 3}$. The lines denote the analytical solutions, and the symbols represent the experimental results. As shown in Figure 15, the two results qualitatively agree with each model.

Table 8. Irregular wave conditions.

\begin{tabular}{ccc}
\hline \multirow{2}{*}{ Case } & \multicolumn{2}{c}{ JONSWAP Spectrum $(\gamma=3.3)$} \\
\cline { 2 - 3 } & $\boldsymbol{H}_{\mathbf{1 / 3}}(\mathbf{m})$ & $\boldsymbol{\omega}_{P}(\mathrm{rad} / \mathbf{s})$ \\
\hline 1 & 0.112 & 2.8 \\
2 & 0.098 & 3.0 \\
3 & 0.087 & 3.2 \\
4 & 0.077 & 3.4 \\
5 & 0.068 & 3.6 \\
6 & 0.065 & 3.7 \\
\hline
\end{tabular}




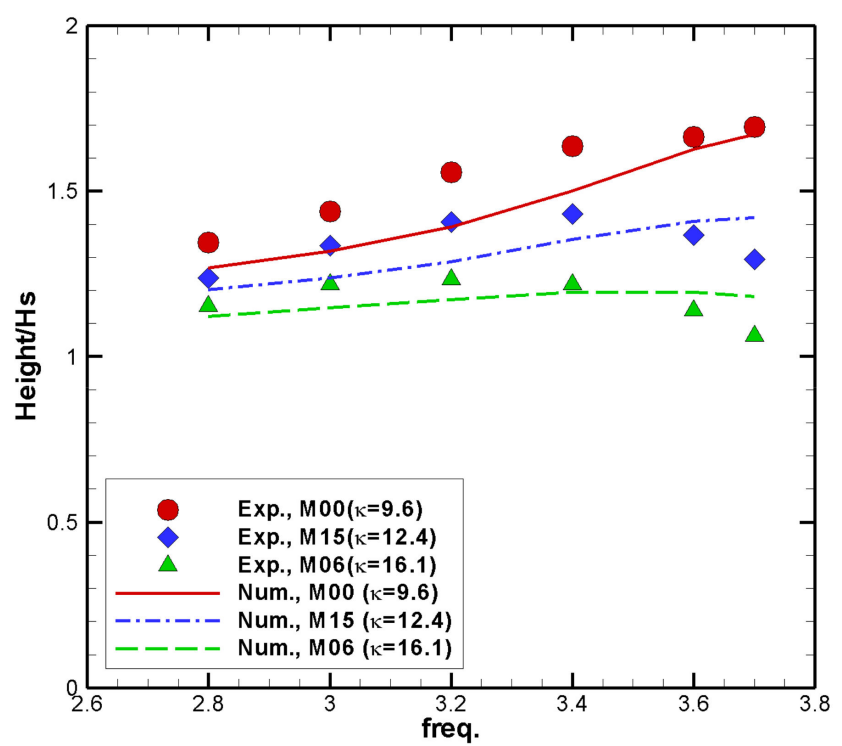

Figure 15. Heave RAO of the HPA with different irregular wave conditions.

Figure 16 shows the time series of the heave motion response and the extracted power at $H_{1 / 3}=0.098 \mathrm{~m}, \omega_{P}=3.0 \mathrm{rad} / \mathrm{s}$. Figure 15 showed that the heave motion displacement is larger for M00 than for M06. For maximum power extraction, a trade-off exists between the value of the PTO damping coefficient and heaving velocity (displacement), as shown in

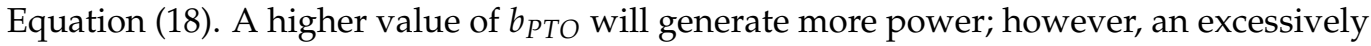
high value of $b_{P T O}$ will decrease the heave velocity, and thus decrease the power output. The extracted power for M06 is proportional to the heave motion displacement and has a maximum peak value of $2.7 \mathrm{~W}$. If scaling up to the full-sized prototype, an electrical power of $8.53 \mathrm{~kW}$ is extracted in the real sea of $H_{1 / 3}=0.98 \mathrm{~m}, T_{P}=6.62 \mathrm{~s}$.

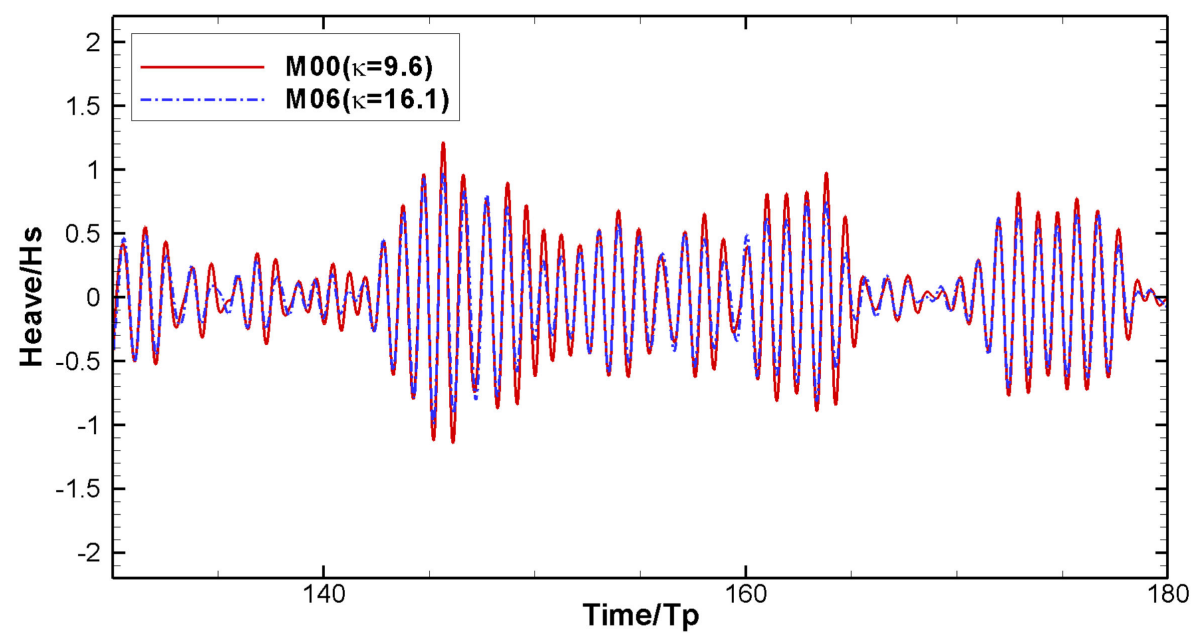

(a)

Figure 16. Cont. 


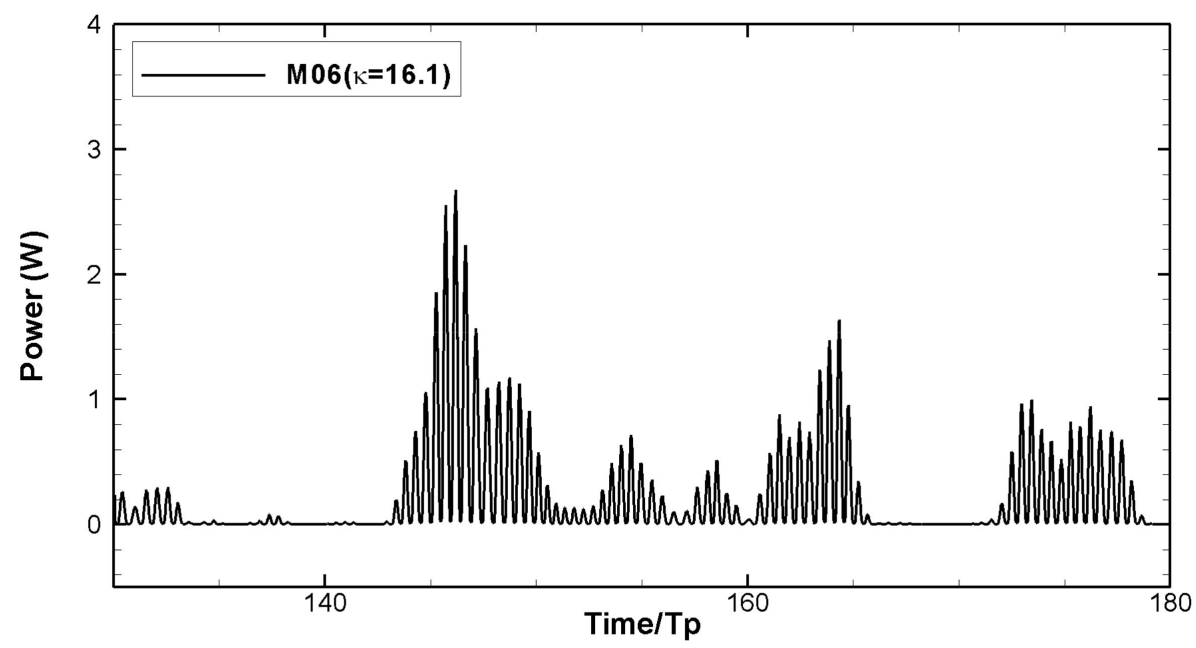

(b)

Figure 16. Time series of heave motion response and extracted power for different PTO damping in irregular waves $\left(H_{1 / 3}=0.098 \mathrm{~m}, \omega_{P}=3.0 \mathrm{rad} / \mathrm{s}\right)$; (a) Heave motion; (b) Extracted power.

\subsection{Motion Responses of Multiple Heaving Point Absorber Connected to Large Semi-Submersible}

Figure 17 shows the motion response of a large semi-submersible. The results of the experiment and numerical analysis showed similar trends. The motion was measured to be almost zero, when the dimensionless wave period was four or more. The results of the motion of the semi-submersible were verified.

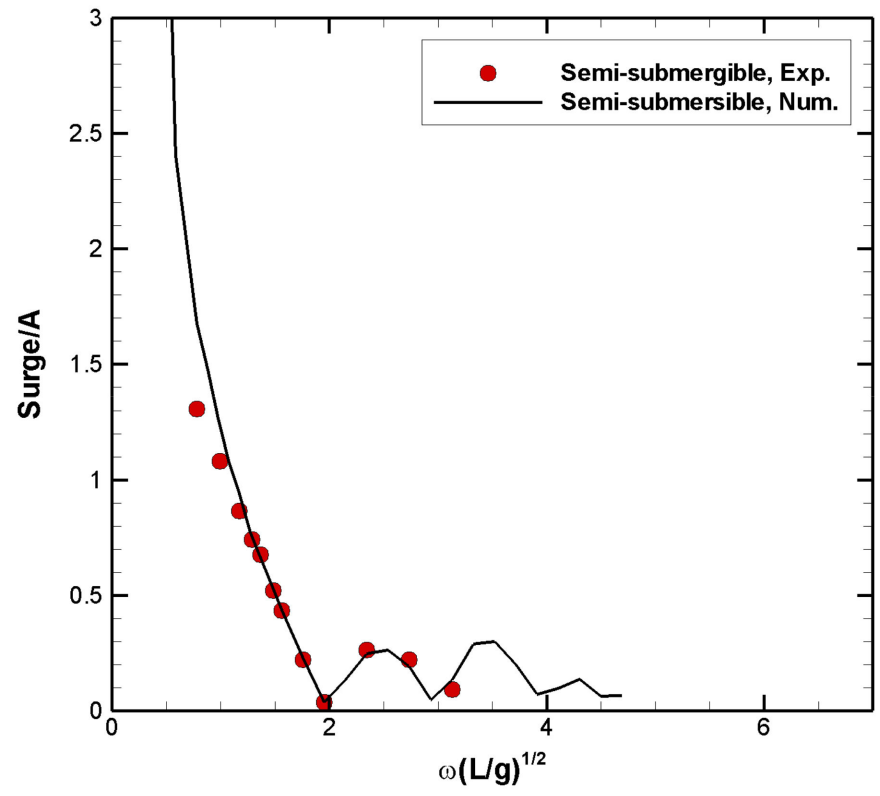

(a)

Figure 17. Cont. 


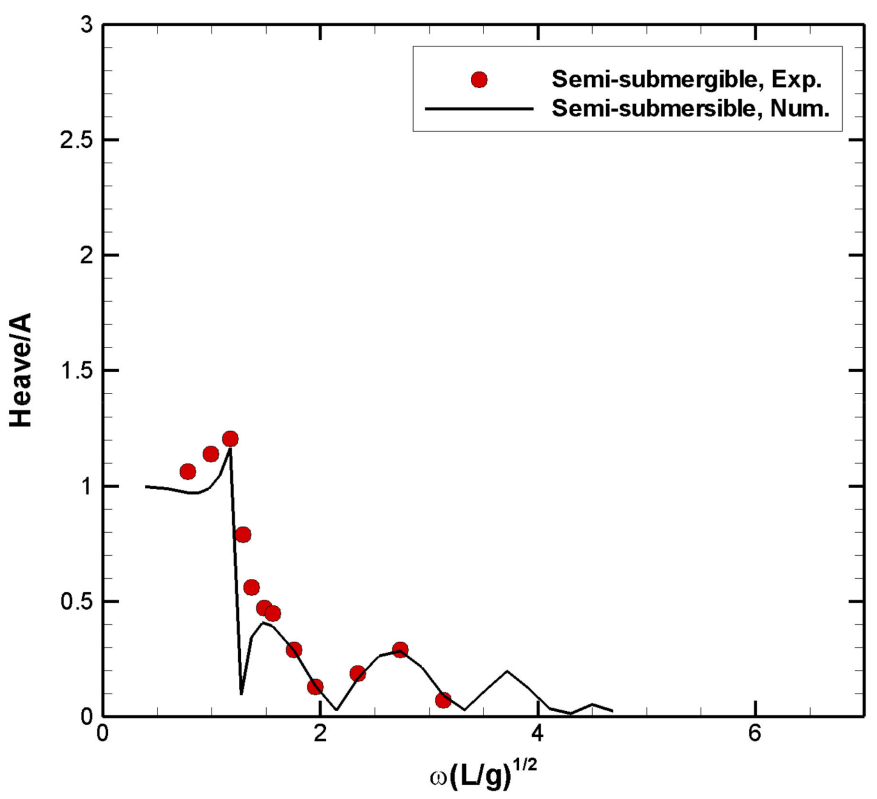

(b)

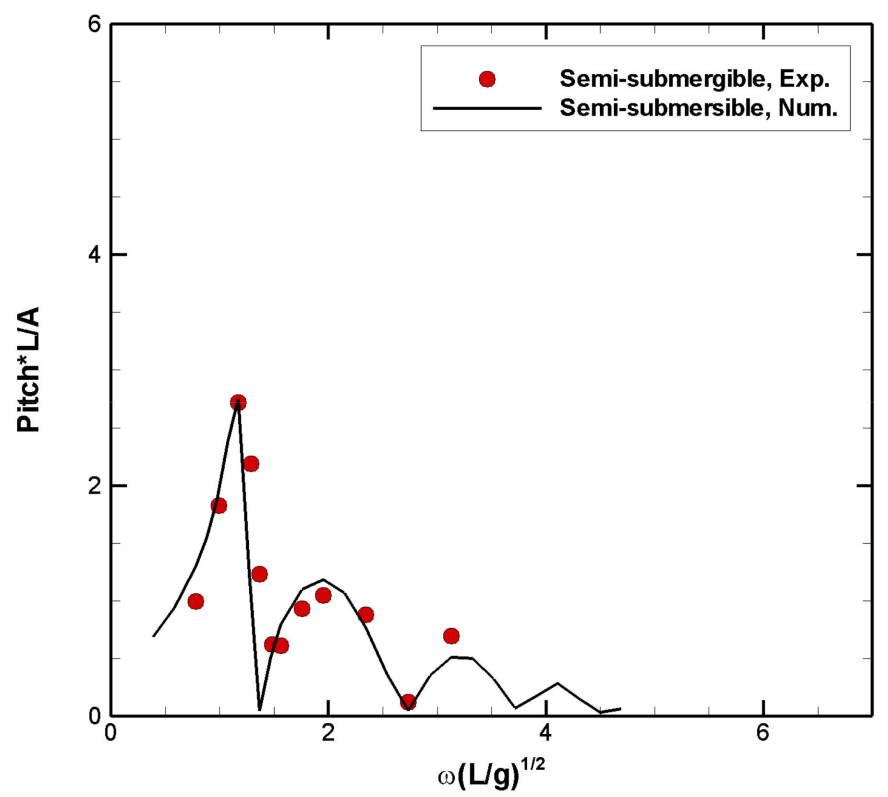

(c)

Figure 17. Motion RAO of large semi-submersible (wave heading angle $=0^{\circ}$ ); (a) Surge; (b) Heave; (c) Pitch.

Figure 18 shows the motion RAOs of the single HPA and multiple HPAs connected to the large semi-submersible structure. The motion RAOs of HPA1 and HPA2 placed on the weather side show a trend similar to that of a single HPA. HPA1 and HPA2, which have a lower damping ratio $(\kappa=9.0)$ compared to the single HPA $(\kappa=9.6)$, have a larger motion response near the resonant frequency (4.5). It is natural that there is less damping, resulting in a larger motion. In HPA2, a larger motion response may be influenced by the scattering waves of a large semi-submersible structure. Compared to the HPAs on the weather side and the single HPA, the HPA3 on the lee side shows a relatively small motion response near the resonant frequency. This is because the incident waves are scattered by the large semi-submersible structure, and HPAs are placed on the weather side. 


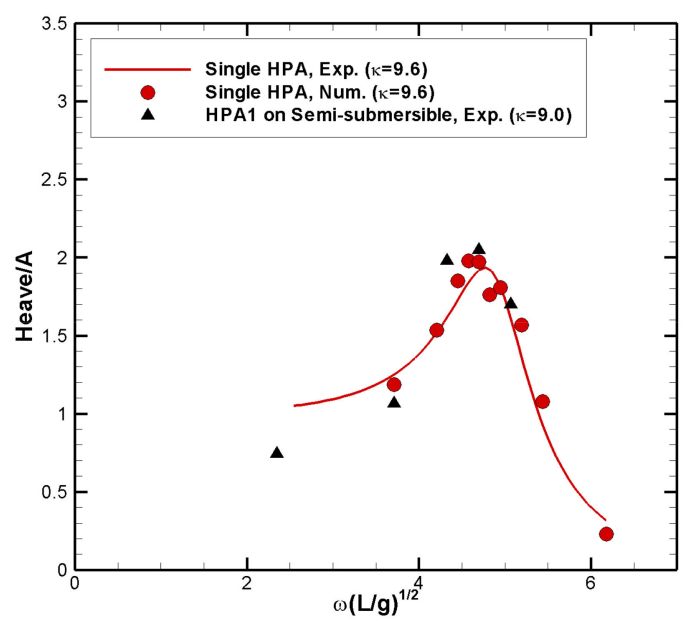

(a)

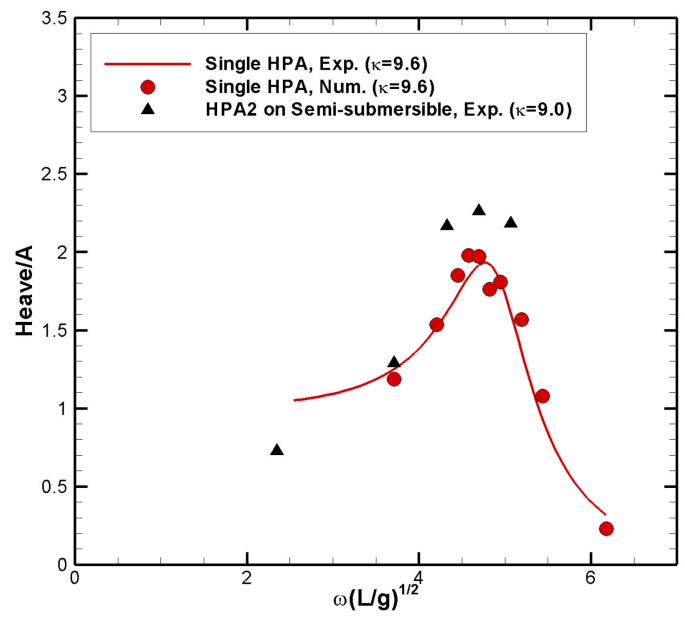

(b)

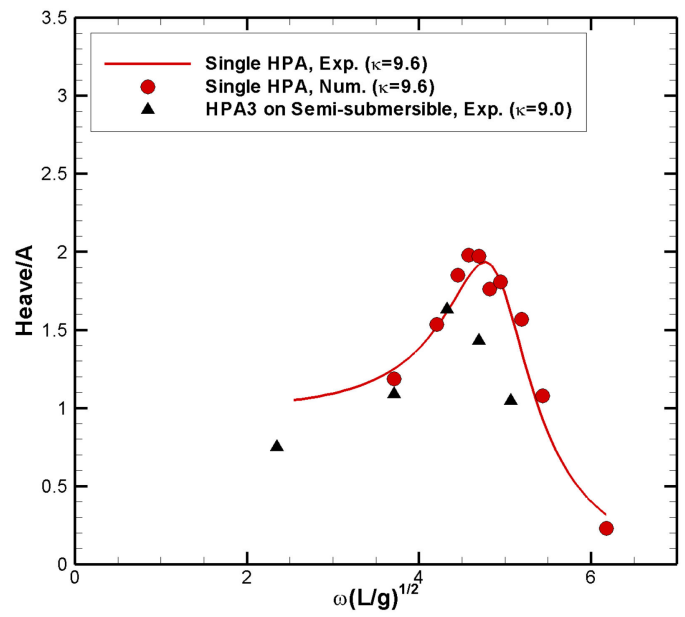

(c)

Figure 18. Motion RAOs of multiple HPAs connected to large semi-submersible; (a) HPA1 (in weather side); (b) HPA2 (in weather side); (c) HPA3 (in lee side). 
When the frequency is less than 4, the motion response of a single HPA tends to be larger than that of the HPAs connected to the semi-submersible. In this frequency range, the large semi-submersible rides the waves and has small heave and pitch motions, which affects the motion of the HPAs, making it smaller than that of a single HPA.

Figure 19 shows the motion history of the HPAs measured for irregular waves. While HPA1 and HPA2 showed similar motion responses HPA3 which is placed on the lee side, showed a different motion response.

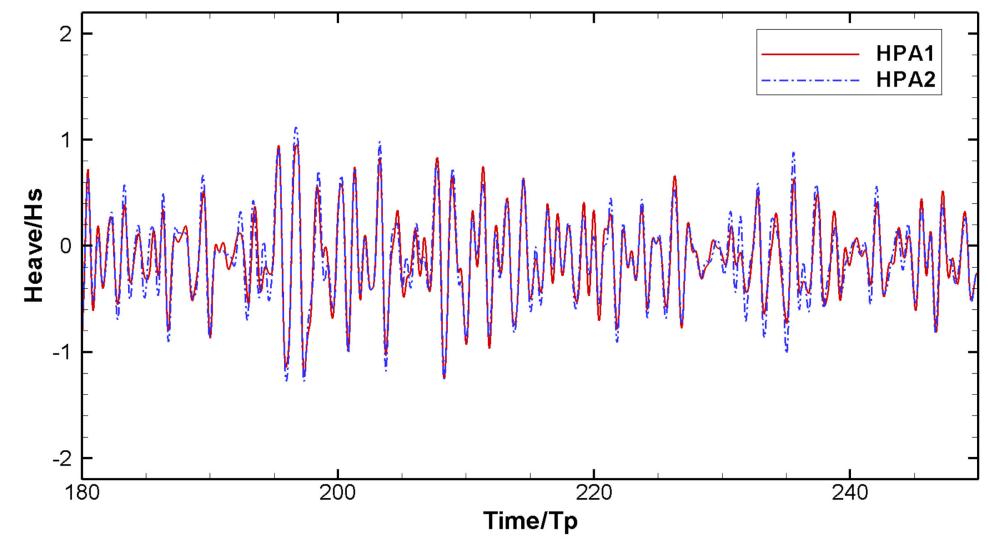

(a)

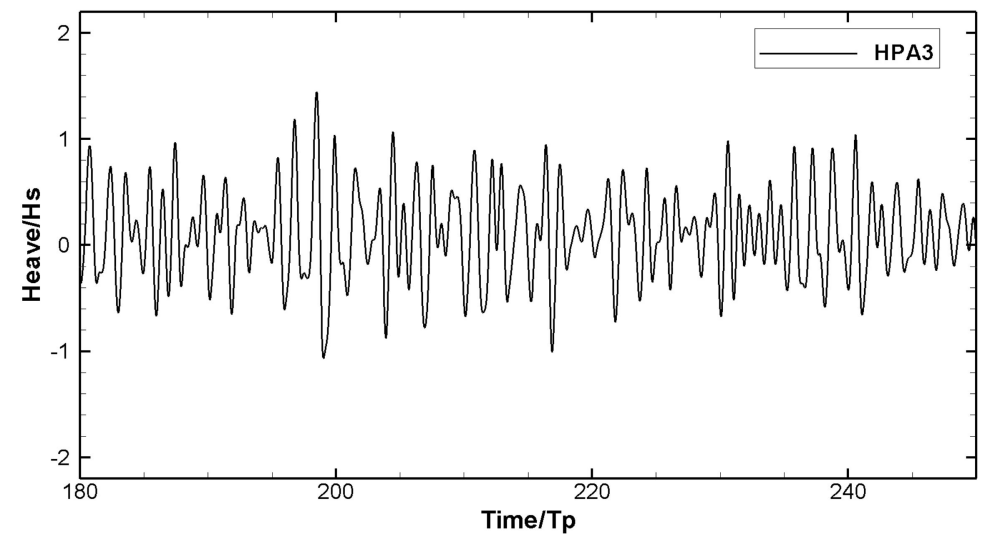

(b)

Figure 19. Heave motion of multiple HPAs connected to the large semi-submersible ( $\mathrm{Hs}=3.0 \mathrm{~m}$, $\mathrm{Tp}=6.67 \mathrm{~s}, \mathrm{Vc}=0.14 \mathrm{~m} / \mathrm{s}$ ); (a) HPA1 and HPA2 (at the weather side); (b) HPA3 (at the lee side).

Figure 20 shows the average and maximum motion responses of HPAs evaluated from the irregular wave test over a 3-h measurement on a real scale. For the single HPA, the result was measured for $1 \mathrm{~h}$ under the same irregular wave condition without a current load $\left(\mathrm{Vc}_{\mathrm{c}}=0 \mathrm{~m} / \mathrm{s}\right)$. The average height was calculated by sampling the heave heights of the HPA based on a zero-up crossing, and the maximum height was the largest value among the samples. As shown in Figure 20a, HPA3 shows smaller motion responses than HPA, HPA1, and HPA2. The motion responses of HPA1 and HPA2 are quite similar. In the results of the maximum height, HPA1 and HPA2 show a slightly larger height than the single HPA, and HPA3 shows a smaller trend. This tendency is similar to the tendency of the motion response presented in the regular wave test. Based on the above results, it can be concluded that the motion response of a single HPA connected to the large semisubmersible is similar to that of a HPAs on the weather side, and the HPA on the lee side shows a lower motion response. 


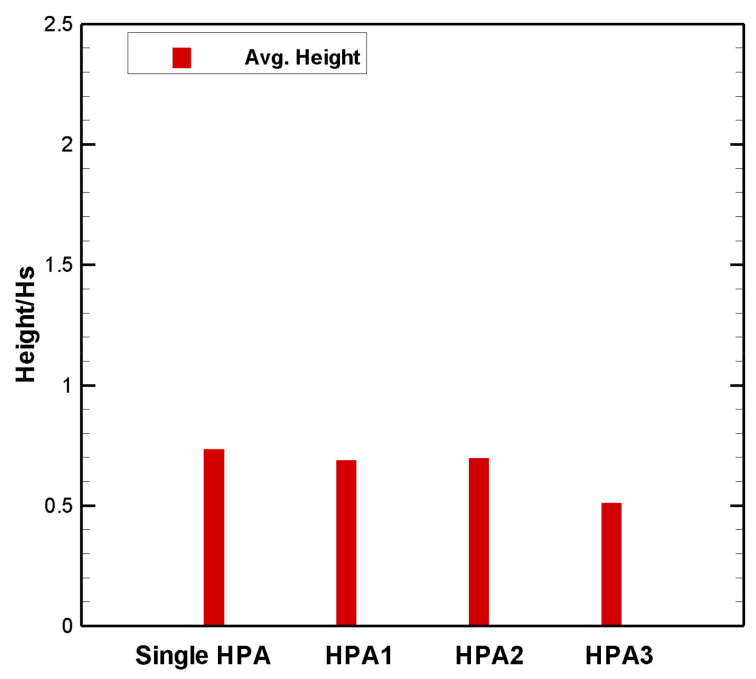

(a)

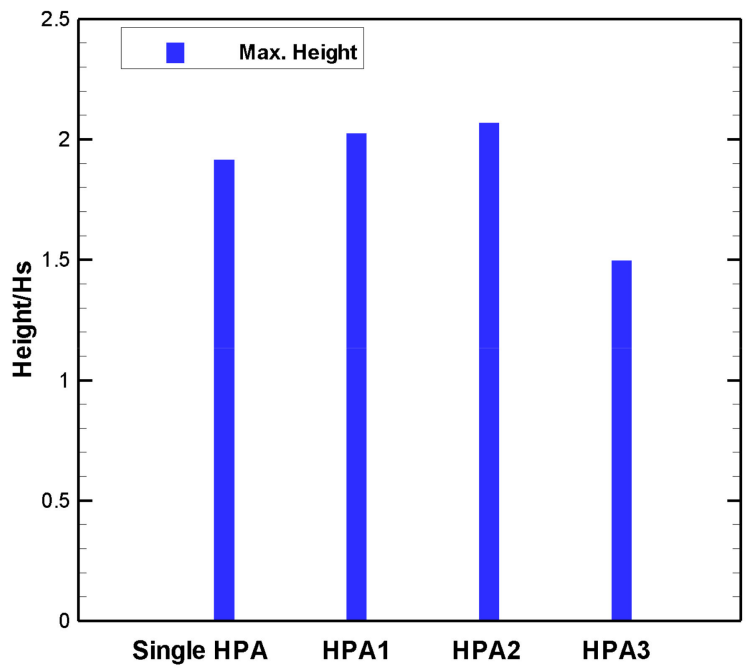

(b)

Figure 20. Motion responses of HPAs in operational condition $(\mathrm{Hs}=3.0 \mathrm{~m}, \mathrm{Tp}=6.67 \mathrm{~s}, \mathrm{Vc}=0.14 \mathrm{~m} / \mathrm{s}$ except single HPA, wave heading angle $=0^{\circ}$ ); (a) Average height; (b) Maximum height.

Figure 21 shows the average height of the single HPA and multiple HPAs connected to the large semi-submersible under different irregular wave conditions. HPAs on the weather side and lee side showed a large difference in response to motion under the operational conditions where $\mathrm{Hs}$ and $\mathrm{Tp}$ are $3 \mathrm{~m}$ and $6.67 \mathrm{~s}$, respectively. However, when $\mathrm{Tp}$ is far from the resonance period of the HPA, the HPAs on the weather side and lee side show similar motion responses. As shown in Figure 18, the HPAs connected to the large semi-submersible structure show a similar tendency as the motion response of the regular wave becomes farther from the resonance period. Thus, the motion response of HPA among irregular waves may have a similar tendency depending on the incident wave condition, even when it is on the lee side. 


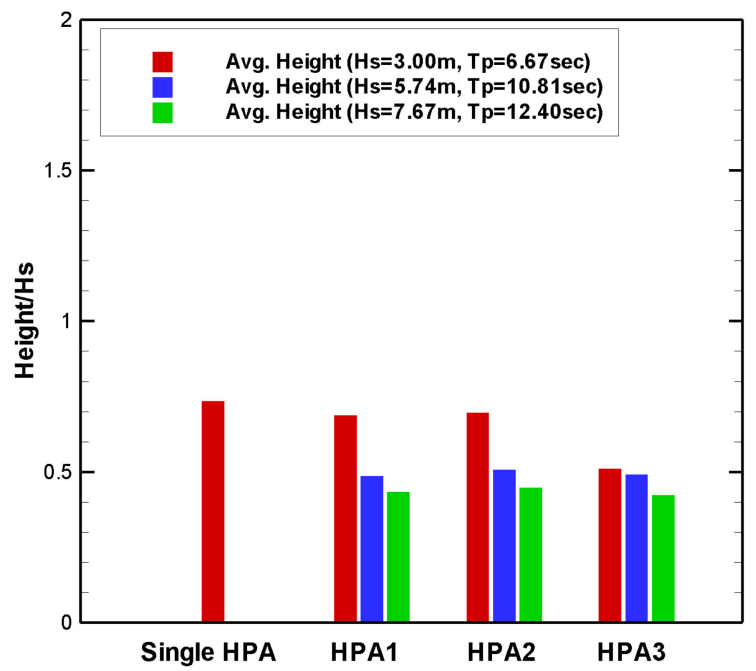

Figure 21. Motion responses of HPAs in various environmental conditions $\left(\mathrm{Vc}_{\mathrm{c}}=0.14 \mathrm{~m} / \mathrm{s}\right.$ except the single HPA, wave heading angle $=0^{\circ}$ ).

\section{Conclusions}

The motion responses of HPAs connected to a large semi-submersible were studied. The motion response for a single HPA moving along a wall-mounted guide was measured using a 1/10 scale water tank model test and validated with the numerical results of the MEEM analysis. In addition, a large semi-submersible and multiple HPAs were manufactured, and model tests were performed for regular and irregular waves on a $1 / 50$ scale in a 3D ocean basin. The following conclusions were drawn by comparing the motion responses of the single HPA and multiple HPAs connected to the large semisubmersible.

- The motion of a single HPA moving along a wall-mounted guide can be predicted using a potential flow analysis based on eigenvalue analysis.

- The motion responses of HPAs connected to the large semi-submersible on the weather side tend to be similar to that of the single HPA among regular waves, and the motion response of HPA on the lee side is less than that of the single HPA.

- The motion responses of HPAs connected to the large semi-submersible among irregular waves tend to be similar to those of regular waves, but if the wave period moves away from the resonance period of HPA, the motion responses of HPAs on the weather side and lee side become similar.

The motion characteristics of HPA connected to a large semi-submersible were investigated. Although the motion response of HPA may vary depending on the shape of the semi-submersible, the results of this study will be helpful to understand the motion characteristics of HPA connected to a large floating structure. The findings of this study may be used in the design of large floating structures and HPA in the future.

Author Contributions: Methodology, K.-H.K. and I.-H.C.; formal analysis, S.P., and J.-R.K.; model test, K.-H.K., S.P., and J.-R.K.; writing-original draft preparation, K.-H.K., S.P., J.-R.K., I.-H.C.; writing-review and editing, K.-H.K. and K.H.; supervision \& project administration, K.H. All authors have read and agreed to the published version of the manuscript.

Funding: This study was funded by the "Development of Predictive Operation \& Maintenance Technologies for Floating Offshore Wind Turbine based on Digital Twin Technology (PNS3910)". We greatly appreciate the support received.

Conflicts of Interest: The authors declare no conflict of interest. 


\section{References}

1. Perez-Collazo, C.; Greaves, D.; Iglesias, G. A review of combined wave and offshore wind energy. Renew. Sustain. Energy Rev. 2015, 42, 141-153. [CrossRef]

2. Kim, H.C.; Kim, K.H.; Kim, M.H.; Hong, K. Global Performance of a KRISO Semisubmersible Multiunit Floating Offshore Wind Turbine: Numerical Simulation vs. Model Test. Int. J. Offshore Polar Eng. 2017, 27, 70-81. [CrossRef]

3. Bae, Y.H.; Kim, M.H. Influence of failed blade-pitch-control system to FOWT by aero-elastic-control-floater-mooring coupled dynamic analysis. Ocean. Sys. Eng. 2013, 3, 295-307. [CrossRef]

4. Bae, Y.H.; Kim, M.H. Coupled dynamic analysis of multiple wind turbines on a large single floater. Ocean. Eng. 2014, 92, 175-187. [CrossRef]

5. Lee, S.; Kim, K.H.; Lee, K.; Park, S.; Hong, K. Large-eddy simulation of offshore wind plants and fatigue load mitigation via pitch control strategies. J. Renew. Sustain. Energy 2017, 10, 033304. [CrossRef]

6. Kim, K.H.; Lee, K.; Sohn, J.M.; Park, S.; Choi, J.S.; Hong, S. Conceptual Design of 10MW Class Floating Wave-Offshore Wind Hybrid Power Generation System. In Proceedings of the Twenty-Fifth International Ocean and Polar Engineering Conference, Kona, HI, USA, 21-26 June 2015.

7. Koh, H.J.; Cho, I.H. Heave motion response of a circular cylinder with the dual damping plates. Ocean. Eng. 2016, 125, 95-102. [CrossRef]

8. Sow, C.L.; Koto, J.; Abyn, H. Semi-submersible heave response study using diffraction potential theory with viscous damping correction. J. Ocean. Mech. Aerosp. 2014, 5, 23-29.

9. Linton, C.M.; Evans, D.V. The interaction of waves with arrays of vertical circular cylinders. J. Fluid Mech. 1990, 215, 549-569. [CrossRef]

10. Evans, D.; Porter, R. Near-trapping of waves by circular arrays of vertical cylinders. Appl. Ocean. Res. 1997, 19, 83-99. [CrossRef]

11. Malenica, S.; Eatock Taylor, R.; Huang, J.B. Second-order wave diffraction by an array of vertical cylinders. J. Fluid Mech. 1990, 390, 349-373. [CrossRef]

12. McIver, P. Wave interaction with arrays of structures. Appl. Ocean. Res. 2002, 24, 121-126. [CrossRef]

13. Siddorn, P.; Taylor, R.E. Diffraction and independent radiation by an array of floating cylinders. Ocean. Eng. 2008, 35, 1289-1303. [CrossRef]

14. Meylan, M.H.; Eatock Taylor, R. Time-dependent water-wave scattering by arrays of cylinders and the approximation of near trapping. J. Fluid Mech. 2009, 631, 103-125. [CrossRef]

15. Li, Y.; Yu, Y.-H. A synthesis of numerical methods for modeling wave energy converter-point absorbers. Renew. Sustain. Energy Rev. 2012, 16, 4352-4364. [CrossRef]

16. Wolgamot, H.A.; Meylan, M.H.; Reid, C.D. Multiply heaving bodies in the time-domain: Symmetry and complex resonances. J. Fluids Struc. 2017, 69, 232-251. [CrossRef]

17. Ropero-Giralda, P.; Crespo, A.J.; Tagliafierro, B.; Altomare, C.; Domínguez, J.M.; Gómez-Gesteira, M.; Viccione, G. Efficiency and survivability analysis of a point-absorber wave energy converter using DualSPHysics. Renew. Erg. 2020, 162, 1763-1776. [CrossRef]

18. Haraguchi, R.; Asai, T. Enhanced power absorption of a point absorber wave energy converter using a tuned inertial mass. Energy 2020, 202, 117740. [CrossRef] 